\title{
The Architecture of Personality in the Context of Work
}

\author{
by \\ Rebecca Ann Hoffner \\ Thesis submitted to the Faculty of the \\ Virginia Polytechnic Institute and State University \\ in partial fulfillment of the requirements for the degree \\ of \\ Master of Science \\ in \\ Psychology \\ Neil Hauenstein, Ph.D., Chair \\ Roseanne Foti, Ph.D. \\ Robert Stephens, Ph.D. \\ May 1, 2006 \\ Blacksburg, Virginia
}

Key Words: Personality, KAPA, Self-Efficacy

Copyright 2006, Rebecca A. Hoffner 
The Architecture of Personality in the Context of Work

by

Rebecca Ann Hoffner

(ABSTRACT)

The purpose of the present study was to replicate Cervone's (2004) study, specifically for a work context. By focusing on the context of work, I believe that a "situationally-sensitive" nomothetic measure of personality for predicting job performance can be developed. My findings indicate that participants were able to identify self-relevant attributes in the context of work and then rate the relevance of each self-relevant attribute to work situations, such that the scores of the self-efficacy items related to those situations rated as relevant correspond with the self-relevant characteristics that were originally identified. Also, the data suggest that while there are several instances of idiosyncrasy in self-perception, there are also many commonalities in both the characteristics believed to be self-relevant and the situations to which those characteristics are relevant. This finding opens up the possibility of using an alternative strategy to develop a nomothetic measure of personality based on idiographic methods. 


\section{ACKNOWLEDGEMENTS}

There are so many people who have made this achievement possible. First and foremost, I would like to thank my advisor and committee chair, Dr. Neil Hauenstein, for his unending support and guidance (not to mention the less than 24 hour turnaround on iteration after iteration of this paper). His time and effort throughout this process have made a difficult journey bearable. He has provided me with encouragement and criticism at just the right times to ensure that the process continued moving forward. I would also like to thank the other members of my committee, Dr. Roseanne Foti and Dr. Robert Stephens, for their contributions to my research through their insightful (albeit difficult) questions and suggestions. I would also like to thank my research assistant, Alan Zedaker, for his help with the seemingly endless hours of pre-coding opscan forms and running subjects through phase 2. His hard work and dedication aided tremendously in the completion of this study. In addition, I would like to thank my friend Cathee for her hours and hours of proofreading the many different drafts that this paper has gone through. Without her, this process would not have gone quite as smoothly.

I would also like to thank my family for their support and guidance throughout this entire process. First, to my five-year-old daughter, Morrigan, I would like to say thank you. You have been patient and respectful of me when I needed to work and couldn't give you the time you deserve. I love you so much and I hope that someday I can convey to you how much you mean to me. Everything I do, I do for you. Next, to my mother, Julie, I would like to say thank you for all of the hours you spent talking with me on the phone. You have always supported my decision to further my education, even though it meant that I would be living 20 hours away. I will never forget our conversations about writing. You encouraged me to get through it, even though it was tough. I did it, Mom, and I couldn't have done it without you. To my father, Grant, thank you. You have always been there, encouraging me in your own way. I have always strived to make you proud. I promise, I will always make sure to "check the oil."

To my sister, Tricia, I want to say thank you. Thanks for always being there to talk to about things other than school. I always appreciated hearing about what was happening with you in ballet, dance line, cheerleading, and life. You make me proud and I hope that I have made you proud. And finally, to my departed brother, John, thank you. Even though I haven't been able to talk to you face to face in over six years, you have always been there with me, supporting 
me through every tough decision I have had to make. I will love you and remember you always. Your silent encouragement will be with me forever. 


\section{TABLE OF CONTENTS}

ABSTRACT

ACKNOWLEDGEMENTS

ii

TABLE OF CONTENTS

LIST OF TABLES

LIST OF FIGURES

iii

V

vii

viii

Chapter

Page

INTRODUCTION

LITERATURE REVIEW

History of the Trait Approach

Evidence of the Utility of the Trait Approach

5

Criticisms of the Trait Approach

Faking and Predictive Accuracy 9

$\begin{array}{ll}\text { Improving the Predictive Accuracy of Trait Measures } & 10\end{array}$

$\begin{array}{ll}\text { Alternative Models of Personality } & 13\end{array}$

Conceptual Models of the Social-Cognitive Approach 14

Self-Schema $\quad 15$

Empirical Evidence of the CAPS Model 15

$\begin{array}{ll}\text { Connectionism } & 17\end{array}$

Knowledge-and-Appraisal Personality Architecture 17

OVERVIEW OF THE CURRENT STUDY 20

METHOD 22

\begin{tabular}{ll} 
Participants & 22 \\
\hline
\end{tabular}

$\begin{array}{ll}\text { Phase } 1 & 22\end{array}$

Procedure $\quad 22$

Schema Development 23

$\begin{array}{ll}\text { Phase } 2 & 23\end{array}$

Procedure $\quad 23$

$\begin{array}{ll}\text { Phase } 3 & 24\end{array}$

Procedure $\quad 24$

Self-Efficacy Scale $\quad 24$

RESULTS $\quad 26$

Modified Replication of Cervone (2004) 26

Frequency Distribution $\quad 27$

$\begin{array}{ll}\text { Analysis of Situational Relevance } & 27\end{array}$

Analysis of Self-Efficacy Ratings $\quad 28$

$\begin{array}{ll}\text { Nomothetic Analysis } & 30\end{array}$

Coding of Phase $1 \quad 30$

Nomothetic Agreement of Situational Relevance $\quad 30$

Top Down vs. Bottom Up Assessment Strategies 32 
Specific Analysis of the Characteristic "Gregariousness" 32

DISCUSSION 34

Discussion of Idiographic Analysis 34

Discussion of Nomothetic Analysis 34

GENERAL DISCUSSION 36

Limitations 37

Weaknesses of Method $\quad 37$

Faking and Self-Efficacy $\quad 37$

$\begin{array}{ll}\text { CONCLUSION } & 39\end{array}$

$\begin{array}{ll}\text { REFERENCES } & 40\end{array}$

APPENDICES 46

A. Instructions for Phase 1 Essay Writing Task 46

B. Bipolar Attribute Scale 47

C. Instructions and Situational Phrases Used in Phase $2 \quad 50$

D. Instructions and Self-Efficacy Items Used in Phase 3

$\begin{array}{ll}\text { FOOTNOTES } & 63\end{array}$ 


\section{LIST OF TABLES}

Page

$1 \quad$ Frequency Distribution of Attributes in Phase 1

2 Frequency of Responses to Characteristics in Phase $2 \quad 66$

3 Number of Situations Rated as Relevant by Individuals Possessing the Characteristic (Schematic) and Individuals Rating the Characteristic Normatively (Normative), the Number of Overlapping Ratings and the Agreement between Each Group.

4 Means, Standard Deviations and Effect Sizes by Level of Relevance and Type of Attribute for Schematic Attributes

5 Means, Standard Deviations and Effect Sizes by Level of Relevance and Type of Attribute for Normative Attributes

6 Situations Rated as Relevant on Average by the Group of Raters for the Characteristic Gregariousness

7 Means, Standard Deviations, and Effect Sizes for Nomothetic Analysis of the Characteristic Gregariousness 


\section{LIST OF FIGURES}

$\underline{\text { Figure }}$

Page

Figure 1. Illustration of one participant's three schematic characteristics with the situations she believed were most relevant to one attribute (organized) and one situation that was generally viewed as relevant to being organized, but was not rated as relevant by this participant.

Figure 2. Illustration of two participants whose bipolar attribute was soft hearted and the situations that the participants believed to be relevant to the attribute.

Figure 3. Illustration of two participants whose self-relevant strength was dependability and the situations that the participants believed to be relevant to the attribute.

Figure 4. Average of participant's mean self-efficacy ratings (and standard error of the mean bars) on those phase 3 items related to the phase 2 situations by relevance level for schematic attributes.

Figure 5. Average of participant's mean self-efficacy ratings (and standard error of the mean bars) on those phase 3 items related to the phase 2 situations by relevance level for normative attributes.

Figure 6. Comparison of Two Individuals with the Same Mean Self-Efficacy Score on a Group of Items but Differing Underlying Characteristics.

Figure 7. Mean self-efficacy appraisals for those items related to situations relevant to the characteristic Gregariousness. 


\section{Introduction}

Personality psychology has been evolving since the 1930s. The trait approach to personality originated with Allport and Odbert's search for trait names in the English dictionary. Since then, trait theorists have continued using statistical techniques in order to simplify these trait names into a meaningful taxonomy of personality. The most commonly used classification is the Big Five, made popular by McCrae and Costa in the 1980s. At the same time, Industrial/Organizational psychologists have been encouraging employers to use personality tests of the Big Five personality traits in their selection procedures (Berry, 2003). However, researchers have struggled with the limited utility of these personality tests in predicting job performance (Hurtz \& Donovan, 2000). If the trait approach is a valid representation of personality, then the weak predictive accuracy of personality test scores is indicative of limitations to the trait approach, limitations to measures used in the trait approach, or limitations to both the theory and the measures. It is unlikely that the problem is measurement-related, as personality assessment instruments are based on a vast amounts of psychometric research. Therefore, the current study uses an alternative theory of personality to develop a personality measure. If a personality assessment instrument developed from an alternative theory of personality ultimately produces better predictive accuracy than trait-based measures, it suggests that the alternative theory of personality is superior to the trait approach.

I have chosen to use the social-cognitive approach to personality for the theoretical underpinnings for the development of this new measure of personality. This approach considers the interaction of the situation and an individual's cognitions and affects (mental schemas) in predicting behavior. Social-cognitive theorists believe that aspects of a situation activate parts of an individual's schemas, which in turn influence behavior (Mischel \& Shoda, 1995). Cervone built on this social-cognitive theory, proposing his KAPA model (knowledge-and-appraisal personality architecture), which provides a method for measuring personality at the idiographic level (2004). It is through the general logic of the social-cognitive approach to personality, and in particular Cervone's KAPA model, that I will develop a new type of measure of personality. The current study is limited to the initial development of the new assessment instrument. Subsequent research will compare the predictive accuracy of this new assessment approach to the traditional trait-based measures of personality. 


\section{Literature Review}

\section{History of the Trait Approach}

The goal of trait theory is "to infer the underlying personality structure of individuals and to compare persons and groups on trait dimensions" (Mischel, 1968, p. 5-6). This is accomplished by identifying an individual's position on a dimension and comparing that position with previously established norms (Mischel, 1968). That is, trait theory is based on individual differences that appear consistently in a large sample. The dimensions discussed by Mischel date back to 1936, when Allport and Odbert conducted a search for all of the "trait names" in the English dictionary (Norman, 1963). Cattell then built on the work of Allport and Odbert by conducting systematic research on personality. By using factor analysis techniques, he was able to identify what he believed were common traits that comprised the "“surface' of the personality sphere" (Cattell, 1945). Over the course of the next few years, Cattell conducted three studies on personality using 35 bipolar scales developed from Allport and Odbert's original list of "trait names." The first study, using only male subjects, revealed 12 factors. In the second study, which also used only male subjects, he was able to replicate 9 of those factors. Then, in the third study, which used female subjects, he replicated some of the original factors, but he also added new factors. He combined the results of these three studies in order to develop the $16 \mathrm{PF}$ (Sixteen Personality Factors) Questionnaire for which he is remembered (Digman, 1996).

Then, in the 1960s, Eysenk developed his three factor model of personality that consisted of Psychoticism, Extraversion, and Neuroticism (PEN). Eysenck believed that biological factors drive each individual's personality on each of these three dimensions and that these dimensions can be further subdivided using more specific terms (Friedman \& Schustack, 2006). Eysenck's model of personality is arranged hierarchically such that those dimensions that drive behavior are at the top, and lower levels contain the more specific components of the three main dimensions. Eysenck's first factor, Extroversion, includes the outgoingness and assertiveness factors of Cattell's model. Neuroticism includes emotional instability and apprehensiveness from Cattell's model. Eysenk's third factor, Psychoticism, is defined as a tendency toward psychopathology, and includes Cattell's factors of tough-mindedness and shrewdness (Friedman \& Schustack, 2006). Eysenck's approach was unique at the time because it argued for the biological bases of personality. However, according to Costa \& McCrae (1995), Eysenck did little to develop validated measures to be used to test whether the traits he described did indeed covary. Instead, 
he proposed the PEN model in the popular press, describing it for the layperson rather than for the scientific community. Thus, although his work was widely known, it was not widely used in research (Costa \& McCrae, 1995).

Also in the 1960s, Norman published his article on the "adequate taxonomy of personality" (1963) in which he identified five factors that he believed comprised the structure of personality. His five factors were Extroversion or Surgency, Agreeableness, Conscientiousness, Emotional Stability, and Culture. These traits were measured using ratings on bipolar descriptions of scale elements that were developed earlier by Cattell. The Extroversion scale included talkative - silent, open - secretive, and sociable - reclusive. Agreeableness was measured by good-natured —irritable, jealous — not jealous, and cooperative - negativistic. Responsible — undependable, scrupulous - unscrupulous, and tidy — careless were part of the Conscientiousness scale. Emotional Stability included poised—nervous/tense, calm—anxious, and composed - excitable. In the scale designed to measure Culture were artistically sensitiveartistically insensitive, intellectual — unreflective, and imaginative — simple. Interestingly, Norman's model languished as Eysenck's PEN model became popular. It wasn't until McCrae and Costa brought attention back to Norman's work that his contribution to personality was truly understood.

However, in the late $1960 \mathrm{~s}$, the popularity of the trait approach decreased dramatically due to the 1968 book Personality and Assessment by Walter Mischel. His book illustrated several problems with the trait approach to personality (discussed in detail in a following section). Further, he stated that "a viable approach to personality must bridge the gap between the principles and methods of general experimental psychology and the problems confronting the personality psychologist concerned with the assessment and modification of complex human behavior" (p. 148) and suggested that personality psychologists pursue alternatives to trait theory. As a result, with few exceptions, the psychological community stopped personality research altogether.

Then, in the 1980s, the trait approach to personality reemerged due largely to the work of McCrae and Costa. In the early 1980s, McCrae and Costa designed the NEO model (Neuroticism, Extraversion, and Openness to Experience) in order to summarize personality trait clusters (McCrae \& Costa, 1985). The trait approach to personality is primarily research driven, rather than based on theory. So, instead of designing testable hypotheses based on an existing 
theory, the theory is induced from the data. This is accomplished by using statistical techniques to derive factors and then labeling the factors logically. When developing the NEO, McCrae and Costa (1985) began with widely used personality scales rather than the trait names used by Allport and Odbert. Using the 16PF developed by Cattell, McCrae and Costa identified three groups of scales and named them Neuroticism, Extraversion, and Openness to Experience (McCrae \& Costa, 1985). Then, in 1985, they compared the NEO with Norman's five factor model and concluded that Norman's (1963) factors did indeed provide an adequate taxonomy of personality (McCrae \& Costa, 1985). So, McCrae and Costa added Norman's factors of Agreeableness and Conscientiousness to the original NEO model. This latter model, more commonly known as the Big Five, is portrayed as "a comprehensive yet parsimonious specification of personality traits" (1985, p. 711). People scoring high on Extraversion tend to be energetic, sociable, talkative, and outgoing. Agreeable people are good natured, courteous, friendly, and warm. Highly Conscientious people are more organized, careful, reliable, and responsible than their less conscientious counterparts. People scoring low on Emotional Stability tend to be nervous, worrying, insecure, and tense. And Open people (scoring high on Openness to Experience) are original, creative, imaginative, and artistic (Friedman \& Schustack, 2006).

Goldberg was also interested in the trait theory of personality. He, however, believed fully in the lexical approach, so rather than beginning with personality scales, as McCrae and Costa, he took advantage of Norman's 1967 trait term inventory (as cited in Goldberg, 1990) and asked 187 college students to rate themselves on 1,710 terms. He then factor analyzed this data and found support for the five factor model. In fact, he concluded that any analysis of a large sample of trait terms from the English language will result in a variant of the Big-Five factor structure (Goldberg, 1990). From this, Goldberg focused his research on the development of a personality inventory for use in the public domain, unlike the NEO-PI, which is proprietary and cannot be freely used by other researchers. His measure, the International Personality Item Pool (IPIP), can be downloaded from the World Wide Web and used without permission (Goldberg, 1999). More recently, Goldberg and his colleagues have been working to implement a version of the IPIP for use on the internet and have been successful in measuring the intended constructs with this new medium (Buchanan, Johnson, \& Goldberg, 2005). 
Evidence of the Utility of the Trait Approach

The trait approach to personality has been adopted by most of the sub-disciplines of psychology in order to predict a wide range of outcomes. The Big Five has been used to predict personality disorders (Duijsens \& Diekstra, 1996), risky behaviors such as drinking and unrestricted sexual behavior (Theakston, Steward, \& Dawson, 2004; Simpson \& Gangestad, 1991), and health behaviors such as eating disorders (Bollen \& Wojciechowski, 2004) and smoking (Shadel, Cervone, \& Niaura, 2004).

Like these other sub-disciplines, Industrial/Organizational psychology has also found uses for the trait approach to personality. The Big Five has been used in studies to show the relationship between scores on personality measures and many different outcomes, including job satisfaction (Skibba \& Tan, 2004; Furnham, Petrides, \& Jackson, 2002; Judge, Heller, \& Mount, 2002) and leadership (Bono \& Judge, 2004; Hui \& Yongxin, 2004). And perhaps the most important outcome personality has been used to predict in $\mathrm{I} / \mathrm{O}$ psychology is job performance. Since the early $20^{\text {th }}$ century, industrial psychologists have encouraged employers to use many types of tests, including personality tests, in their selection procedures (Berry, 2003). The beliefs supporting the use of personality tests were that personality could help explain and predict behavior (Tett, Jackson, \& Rothstein, 1991) and that personality measures demonstrate "meaningful relationships with important organizational outcomes and provide incremental validity beyond cognitive ability tests" (Dwight, Wolf, \& Golden, 2002, p. 2208).

Barrick and Mount (1991) conducted a meta-analysis of studies that examined the criterion-related validity of personality for selection purposes. They found that Conscientiousness is a consistently valid predictor of job performance (corrected correlations ranging from .20-.23) for almost all types of jobs and appears to tap into traits that are important to accomplishing work tasks. They also found that for jobs in which significant interaction with others is necessary, managers and sales occupations for example, Extraversion is a valid predictor of job performance (corrected correlations of .15-.18). Further, Barrick and Mount hypothesized that Emotional Stability would be a valid predictor of job performance; however, their reported correlations were relatively low. They posit that this could be due to range restriction because extremely neurotic individuals are likely not a part of the labor force. They suggest that there may be some level of Emotional Stability that is "enough," beyond which the predictive utility of Emotional Stability is minimized in the job performance domain (Barrick \& 
Mount, 1991). Their results also suggest that Agreeableness is not an important factor in predicting job performance. One of their most interesting findings is that Openness to Experience predicted "training proficiency," a sub-facet of job performance, but was not a valid predictor of the other sub-facets. They explain this finding by stating that open people tend to be more receptive to training because they are more likely to have a desire to learn (Barrick \& Mount, 1991). However, it is important to note that in their meta-analysis, they included studies that did not explicitly measure the Big Five and instead categorized each of the scales used into the Big Five dimensions (or a sixth Miscellaneous dimension).

Also in 1991, Tett et al. meta-analyzed the validity of personality to predict job performance. In addition, they investigated several moderators of the validity of personality measures. Drawing from the findings of Guion and Gottier (1965), who suggested that studies of the relationship between personality and performance produce better results when empirically driven rather than theoretically based (Bradley, 2003), they investigated the justification given in the original study as a potential moderator. More specifically, for those studies in which the researchers provided a theoretical rationale for the relationship between personality and performance, Tett et al., considered the study to be confirmatory in design. On the other hand, when the researchers did not use theory to drive the inclusion of personality, Tett et al. considered it an exploratory strategy (Bradley, 2003). Tett et al. further hypothesized that there exist situations in which a personality trait would be negatively related to job performance. In order to adjust for the direction of the relationships found in the studies they reviewed, they aggregated the absolute values of the reported correlations (Bradley, 2003). From their metaanalysis, Tett et al. concluded that for studies based on theory (confirmatory), personality is a better predictor of job performance and that Agreeableness is most strongly related to job performance (Bradley, 2003).

Another meta-analysis investigating the relationship of personality and job performance was conducted by Salgado (1997). The prior meta-analyses discussed were conducted in the United States and Canada, so the question of generalizability across cultures had not been addressed. Thus, the purpose of Salgado's (1997) meta-analysis was to examine whether personality factors are valid predictors of job performance in the European Community. He found a positive correlation between Conscientiousness and job performance (corrected $r=.25)$ and also between Emotional Stability and job performance (corrected $\mathrm{r}=.19$ ). 
Most recently, Hurtz and Donovan (2000) used meta-analysis to estimate the validity of Big Five personality measures. Responding to concerns expressed regarding the categorization techniques used by Barrick and Mount (1991) in their meta-analysis, Hurtz and Donovan (2000) looked specifically at studies that included a measure of the Big Five personality traits. They estimate that the true validity of Conscientiousness, the best predictor of job performance among the Big Five traits, ranges from .15 to .26 across occupations. This finding implies that, even at its highest validity, Conscientiousness can only explain approximately $5 \%$ of the variance in job performance. Reported validities for the remaining Big Five traits are even lower: Emotional Stability $\left(\rho_{\mathrm{v}}=.13\right)$, Agreeableness $\left(\rho_{\mathrm{v}}=.11\right)$, Extraversion $\left(\rho_{\mathrm{v}}=.09\right)$, and Openness to Experience $\left(\rho_{\mathrm{v}}=.06\right)$.

Barrick and Mount (1991) concluded that personality test scores account for relatively small amounts of variance in job performance relative to general aptitude. It is clear that this conclusion also was supported by the other major meta-analyses of the personality-job performance relationship. However, personality tests continue to appeal to organizations for use in selection batteries for two reasons. First, the personality dimension means of the racial subgroups identified as protected by the Uniform Guidelines are equal to that of Caucasians. As a result, using personality dimension scores to predict job performance will not result in adverse impact against the protected racial sub-groups. Second, the personality dimensions that predict job performance are not correlated with measures of general aptitude. As such, the job performance variance captured by personality dimensions is additive with that captured by general aptitude (Schmidt \& Hunter, 1998).

\section{Criticisms of the Trait Approach}

Throughout the history of the trait approach, there have been several criticisms regarding its use. First, when traits are used to explain behaviors, the argument is circular. Mischel (1968) illustrates this by saying, "nothing is explained [. . . ] if the state that we have attributed to the person from his behavior is not invoked as the cause of the behavior from which it was inferred" (p. 42). For example, if a person is outgoing and sociable, he is rated high on Extraversion. We call him an Extrovert and use this label to predict future behavior; he will be outgoing and sociable in the future because he is high on Extraversion.

A second problem with trait theory explained by Mischel (1968) is that the situation in which the behavior occurs is not taken into consideration. Funder (2001) furthers this idea, 
asserting that to properly study personality, three elements must be incorporated: the person, the situation, and the behavior. By assuming that personality is stable over time and across situations, trait theory does not address the full breadth of the personality triad and thus will never be fully able to accurately predict behavior. This is a fundamental and especially important issue. Even Cattell, a pioneer of the trait approach, didn't intend for the situation to go unconsidered: "Personality may be defined as that which tells what a man will do when placed in a given situation" (1966, p. 25).

The third, and most notable, problem illustrated by Mischel (1968) regards the modest utility of personality traits as explanatory variables. Mischel (1968) admits that trait theory originated from logical and plausible assumptions, but goes on to say that it has not been adequately supported empirically. It is currently accepted in psychology that the correlation between behavior in one situation and another will more often than not reach $r=.40$. However, this means that only $16 \%$ of the variance in behavior is due to individual differences (Funder, 2001).

Another criticism that has been expressed is in regard to the claim made by McCrae and Costa that personality traits have a genetic basis and reach maturity in early adulthood, after which little or no change occurs (1996). If their claim is true, an individual's personality as measured by the Big Five will be stable over time; however, many researchers have suggested that an individual's personality is influenced by changes over the course of life (Srivastava, John, Gosling, \& Potter, 2003). Specifically, Srivastava et al. (2003) found that Conscientiousness continues to increase beyond age 30, Agreeableness increases the most during a person's 30s, and Neuroticism declines after age 30 for women. These findings are inconsistent with the proposition that personality traits are stable over time.

Borsboom, Mellenbergh, \& van Heerden (2003) bring up another important issue in personality measurement. Trait measures of personality like the Big Five are measuring "locally irrelevant constructs" in which within subject change over time is considered error variance, and only between subjects differences are considered. These locally irrelevant constructs give no answer to the ontological question: "Why do people behave the way they do?" In reality, trait measures of personality work on circular logic, as described above. To address the process question properly, and to provide the most relevant and useful personality information, Borsboom et al. (2003) advise a focus on locally homogeneous constructs in which individuals 
change over time, but at rates that are similar between people. By finding the patterns of change across people over time (differing situations), a more accurate measure of personality will be developed. The difficulty with this process is that measurement will need to begin at the idiographic level, rather than the nomothetic (e.g., Big Five), in order to understand individual differences over time.

Faking and predictive accuracy. Beyond the general criticism of the trait approach mentioned above, there is the specific criticism about the effect of faking when using self-report personality test scores to predict job performance. While there is little doubt that faking is possible on personality tests, there is an ongoing debate as to whether or not faking can undermine their predictive accuracy. In fact, several studies have been conducted showing that when prompted to "fake good," participants are very successful in distorting their responses (e.g., Hough, Eaton, Dunnette, Kamp, \& McCloy, 1990; Mueller-Hanson, Heggestad, \& Thornton, 2003). However, the field is divided regarding the effect of faking on the predictive accuracy of personality test scores. Several researchers believe that faking undermines the predictive accuracy of personality tests and can lead to poor hiring decisions. These researchers believe that applicants are motivated to make a good impression, so in a selection setting, they will 'deliberately search for cues regarding others' impressions of them and attend selectively to information that is relevant to making the right impression" (Leary \& Kowalski, 1990, p. 36). Moreover, they attempt to convey an image that matches the characteristics of the prototypical employee for the job. Furthermore, Mueller-Hanson et al. (2003) assert that this distortion will change the rank order of applicants, specifically in the portion of the scale likely to lead to positive hiring decisions (the upper range in most cases). This leads to an increase in bad hiring decisions because the "fakers" have a better chance of getting hired.

In contrast, other researchers believe that although faking does happen, it is not a cause for concern. Nicholson and Hogan (1990) assert that self-report measures of personality are not inaccurate due to the effects of social desirability. In addition, they believe that social desirability and personality characteristics are correlated due to the overlap in content between them, as evidenced by that fact that using social desirability scores to correct for faking appears to remove some of the true score variance on other personality dimensions (Ones, Viswesvaran, \& Reiss, 1996). Rosse, Stecher, Miller, and Levin (1998) takes this argument further, asserting that socially desirable responding is a function of both response distortion (faking) and "self- 
deceptive positivity," which is itself an individual difference in personality. Another argument that supports the idea that faking is not an issue in selection comes from the impression management literature. Leary and Kowalski (1990) believe that because "people's self-beliefs operate to constrain self-presentations by providing information regarding the probability that they can successfully foster particular impressions" (p. 40), applicants will hesitate to portray themselves in a manner that is extremely inconsistent with their self-images because they may not be able to live up to these expectations if they are hired. Additionally, they suggest that most people believe that lying is immoral, and therefore will refrain from making extremely inconsistent claims about themselves.

\section{Improving the Predictive Accuracy of Trait Measures}

For the most part, researchers who believe in the utility of traditional trait measures have continued to advocate their use for selection. However, there have been attempts to increase the predictive accuracy of personality test scores. One alternative perspective is based on interactionism, in which it is assumed the person and the situation interact to create behavior. This theory incorporates each of the three parts of the personality triad described by Funder (2001): the person, the situation, and the behavior. Following from this perspective, Bing, Whanger, Davison, \& VanHook (2004) attempt to incorporate the situation into the measurement of personality. They state that the noncontextual personality items are subject to interpretation. That is, participants may respond differently, depending on the particular situation in which they imagine themselves when determining their response to the item. The item "I am a leader," for example, may invoke a work context or a social situation. The variance in respondents' framesof-reference on the personality test can be a source of unwanted variance that influences the low predictive validities of the Big Five constructs. In order to control the respondents' frames-ofreference, Bing et al. added the words "at work" to each item from the NEO-PI-R Conscientiousness Scale (Bing et al., 2004). Even though they were able to demonstrate that the frame-of-reference provides incremental validity beyond cognitive ability and noncontextual personality, the amount of difference in correlations reported was small (contextual $r=.51$ vs. noncontextual $\mathrm{r}=.42$ ). Although framing personality questions within a context may slightly improve predictive accuracy, it raises a theoretical conundrum. Can a personality test where all items are contextualized to a situation (e.g., work) still be considered a measure of personality traits? It is difficult to provide a rationale for an affirmative response to that question. By 
definition, traits reflect a structure of personality that supposedly impacts all aspects of behavior. Contextualizing personality test items may improve predictive accuracy slightly, but it does so at the cost of undercutting the theoretical framework upon which the concept of personality traits rests.

This strategy was also employed by Schmit, Ryan, Stierwalt, and Powell (1995). In their first study, they divided participants into four groups. The first group responded to an unaltered personality inventory (NEO-FFI), following the original test instructions. The second group also completed the unaltered NEO-FFI, but received instructions to respond as if they were applying for a job as a customer service representative. The other two groups completed an altered form of the NEO-FFI, in which each item was appended to include a reference to a work context. One group received this measure and the original instructions, while the other received the job application instructions. They found differences between groups that were affected by both the frames-of-reference in both the personality measure and in the instructions. However, the effect of these differences on the overall validity of the measure was not certain. They conducted study 2 in order to examine whether the frame-of-reference was creating socially desirable responding, which would be detrimental to validity, or self-presentation effects, which would increase the validity of the measure. For this study, they administered the NEO-PI-R Conscientiousness scale to one group of participants (half of this group receiving the original instructions and the other half receiving the job application instructions) and an altered form of this scale, appended to reference a school context, to a second group (half of this group receiving the original instructions and the other half receiving the job application instructions). They also obtained college cumulative GPAs for each participant. In study 2, they found support for the selfpresentation hypothesis, suggesting that participants in the application/work context conditions presented themselves more accurately based on comparisons of conscientiousness ratings and college GPA. Overall, this study provides evidence to support that the validity of personality measures will not be decreased by using the frame-of-reference technique (Schmit et al., 1995).

The second strategy used to improve the predictive accuracy of personality test scores has been to carefully link trait measures included in the selection battery to the job specifications. For example, Raymark, Schmit, \& Guion (1997) used the Personality-Related Position Requirements Form (PPRF) to identify the aspects of work that should be related to differences between people in personality dimensions. In their study, Raymark et al. (1997) asked 
psychologists to rate the importance of each of twelve dimensions derived from the Big Five on statements that might be seen in a job analysis. They found high agreement between incumbents on ratings of the importance of the PPRF's behavior clusters for a job, and suggest that using statistical methods to combine these ratings may result in information regarding specific jobs that is relevant to personality. However, the authors later suggest that the Big Five may not be able to adequately describe all work-related traits. This research shows that using modified trait measures of personality, even when theoretically based on the interactionist perspective, adds little to the field of Industrial/Organizational psychology.

Despite these limited findings, Tett and Burnett (2003) pursued this line of reasoning, stating that situations influence the "activation" of traits, which ultimately determines the behavior expressed. That is, the relevance of a specific trait in a given situation influences behavior such that highly relevant traits will have the largest impact on behavior expression. In their model, situations are broken into three components: organizational, social, and task. These components have a moderating effect on the relationship between personality traits and work behavior. In addition, the researchers propose that some situations may overpower personality traits and thus have a direct effect on behavior (Tett \& Burnett, 2003). They suggest that job analyses should include a process of identifying the situational cues that activate traits that are relevant or detrimental to the job and the organization. Further, Tett and Burnett (2003) assert that by using their model, there will be an increase in the predictive power of traits in a given situation. However, this model has not yet been validated for this use.

Motowidlo, Borman, and Schmit took this idea even further, suggesting that performance should be broken down into task and contextual components (1997). Task performance is conceptualized as manufacturing activities (transforming raw materials into final products) and operational activities (sales, planning, managing, etc.). Contextual performance, on the other hand, does not directly involve the production or sale of goods or services, but rather includes functions that help to maintain the organizational environment (helping others, following rules, and being enthusiastic). They assert that while cognitive ability is the best predictor of task performance, personality variables are necessary for predicting contextual performance (Motowidlo et al., 1997). Therefore, selection decisions should be made on the basis of both cognitive ability and personality, to the extent that the organization values task and contextual performance, respectively. 
Thus, although some researchers have been able to provide an increase in the validity of personality testing for use in personnel selection and others have proposed models that offer some promise, the approaches described above are limited. Because they are based in trait theory, it is unlikely that there will be large increases in the predictive accuracy of personality measures. It appears that the potential utility of personality in predicting job performance will never be realized by relying on the trait approach. Research has shown that general mental ability is the best predictor of job performance with correlations of approximately .50 (Schmidt \& Hunter, 1998), while personality doesn't even come close to this level of prediction. Perhaps approaching the personality-work performance issue from an alternative theoretical approach to personality will improve predictive accuracy. In particular, an assessment instrument based on an alternative model of personality may well improve predictive accuracy to levels approaching that seen when using general aptitude.

\section{Alternative Models of Personality}

In spite of the popularity of the trait approach to personality, there are several other perspectives that do not require the assumption of the existence of personality traits to explain behavior. As mentioned previously, the current study utilizes the social-cognitive approach to personality as the foundation for the attempt to develop a new method for measuring personality.

There are four main features of social-cognitive theory that set it apart from other personality theories. First, the social-cognitive approach is based on the assumption that both cognitive and affective processes have social foundations. Social-cognitive theory also views personality as an emergent property of the interactions of person factors (cognitions and affects) and situational variables that are reciprocal (Cervone $\&$ Shoda, 1999). Second, social-cognitive theory attempts to explain both the stability and variability of behavior in contrast to the trait perspective that considers within person variance across time as error variance. The third feature regards the research practices of social-cognitive theory. Not only do researchers in this area use correlational strategies to determine relationships between variables, they conduct experiments designed to clarify causal relationships as well. Finally, like the name implies, social-cognitive theory is social in nature. Its aim is to integrate the effect of social interactions, which are an integral part of the situation, to form a comprehensive theory of personality (Cervone \& Shoda, 1999). Based on these features, I believe that the social-cognitive perspective holds the most promise for the development of an assessment instrument that could 
be used to predict job performance. Specifically, I believe that an individual's behavior at work is necessarily different from that person's behavior in other situations, such as a social gathering. These differences are regarded as error variance by trait theorists, but social-cognitive theorists believe that this variance is important when discussing personality. In order to predict performance on a job using personality, the context must be taken into consideration. Conceptual Models of the Social-Cognitive Approach

Since the early 1970s, Mischel has promoted the social-cognitive approach to personality, discussing extensively the stable if...then ... behavioral signatures of individuals $(1973,1979)$. More recently, Mischel and Shoda (1995) integrated Mischel's early ideas into a model they labeled the "cognitive-affective personality system" (CAPS). They proposed their theory as an attempt to account for both the stability of personality and the variability of behavior across different situations. They assume that individuals differ in "the accessibility of cognitiveaffective mediating units" and "the organization of relationships through which these units interact with each other and with psychological features of situations" (p. 246). The most important aspect of this theory is that it incorporates the role of the situation into the conception of personality. However, Mischel and Shoda assert that the situation is not merely a simple stimulus that invokes a given response, but rather that specific aspects of each situation activate cognitive and affective internal reactions that are based on an individual's prior experiences (1995). From cognitive psychology, their theory draws the ideas of schemas that individuals develop over the course of a lifetime, suggesting that individual differences in schemas will necessarily result in individual differences in behaviors, even in the same situation. Further, their theory captures the process of development of stable patterns of behavior in situations called if...then ... behavior signatures (Mischel \& Shoda, 1995). Using these behavior signatures, this theory is able to account for both the stability of personality and the variance that is dependent on the situation.

The CAPS model focuses specifically on five types of cognitive-affective units that are believed to act as personality mediators between the situation and the behavior. These are encodings - construal of self, other people, situations (schemas); expectancies - beliefs about outcomes in a given situation or about an individual's self-efficacy; affects - feelings, emotions, and affective responses; goals and values; and competencies and self-regulatory plansstrategies for organizing action and affecting outcomes related to goals (Mischel \& Shoda, 
1995). Mischel and Shoda say that these units interact dynamically and influence each other in a system. Further, individuals are supposed to differ in each unit as well, resulting in a complex array of potential influences on individual differences. However, the organization of relationships in this system is assumed to be stable in each individual, suggesting that if the structure can be understood by using the if ...then ... signatures of an individual, then behavior can be predicted (Mischel \& Shoda, 1995). In summary, CAPS suggests that features of the situation are encoded by a mediating unit, activating a subset of units and generating cognition, affect, and behavior in response. These mediating units can be activated, inhibited, or unaffected, depending on the features of the situation, and different combinations of activation lead to different cognitions, affects, and behaviors (Mischel \& Shoda, 1995). In this way, the system accounts for the nonrandom variance in behaviors across situations and the relative stability of personality over time.

Self-Schema. Mischel and Shoda's CAPS model incorporates the self-schema in order to provide a comprehensive understanding of the structure of personality. The concept of selfschema was developed by Markus in 1977. In her study, she argued that at any given time, the amount of stimulation available is much greater than an individual can process. Therefore, decisions must be made spontaneously regarding which information to attend to that are based on cognitive structures, called schema, that encode and represent information (Markus, 1977). A significant amount of the information that must be processed by an individual regards $\mathrm{him} /$ herself; therefore, there must exist cognitive structures that are involved in processing this information (Markus, 1977). In her 1977 study, Markus proposed the existence of these structures and stated "self-schemata are cognitive generalizations about the self, derived from past experience, that organize and guide the processing of self-related information contained in the individual's social experiences" (p. 64). In 1977, this was a novel concept. However, it has become widely accepted and today is often used in research (e.g., CAPS). The study described below uses self-relevant schema in order to assess personality at the idiographic level of analysis. Empirical Evidence of the CAPS Model

In order to test the expectation that behavioral signatures are linked to self-perceptions about consistency, Mischel and Shoda (1995) reexamined data collected in 1982 by Mischel and Peake. Mischel and Shoda hypothesized that students' perceptions of their own consistency would be predicted by the intraindividual stability of their behavior signatures (Mischel, 2004). 
They found that for individuals who saw themselves as consistent in Conscientiousness, the average if...then... signature stability correlation approached .5, as opposed to near zero correlations for those who viewed themselves as inconsistent (Mischel, 2004). This suggests that there is a relationship between the impression of consistency and the stability of the behavioral signatures of individuals.

Following from the evidence provided by Mischel and Shoda (1995, 2004), MendozaDenton, Ayduk, Mischel, Shoda, \& Testa (2001) examined the implications of Person x Situation $(\mathrm{P} \times \mathrm{S})$ interactions on encoding and mental representations of the self. In the first of their studies, participants listened to a series of stories regarding negative experiences relevant to college students. Then they were asked to encode themselves using either a broad, dispositional trait ("I am a(n)___ ”) or with a disposition followed by a situation ("I am a(n) when

"). After repeating aloud the phrase they had written, they were asked to designate their affective state. The results of this experiment suggest that there is a causal relationship between unconditional self-encoding (broad dispositions) and negative affect. That is, the inclusion of a specific situation acts as a buffer for negative affect (Mendoza-Denton et al., 2001).

Study two aimed to investigate the influence of interactionist self-encoding on social perception. The researchers believed that by using $\mathrm{P} \times \mathrm{S}$ interactions, a more complex representation would be formed, meaning more knowledge would be available, which in turn would decrease the likelihood of global stereotype endorsement (Mendoza-Denton et al., 2001). They found that interactionist self-encoding did indeed lessen the use of global stereotypes, suggesting that social perceptions could be enhanced by using this type of encoding (MendozaDenton et al., 2001). However, these researchers still have not addressed the "ultimate goal...to articulate the psychological structure that underlies this organization within the personality system" (Mischel \& Shoda, 1995, p. 259).

The CAPS model has also been used in several different applications. These include willpower and delay of gratification (Mischel \& Ayduk, 2004), maladaptive behavior (Shoda \& Smith, 2004), self-regulation and attentional control (Mischel \& Ayduk, 2002), and cultural differences (Mendoza-Denton, Shoda, Ayduk, \& Mischel, 1999). These studies provide further evidence for the utility of the CAPS model. 


\section{Connectionism}

Another potential alternative model of the social-cognitive approach can be inferred from connectionism. Connectionist theory believes that a connectionist network exists that contains processing units that are interconnected by unidirectional links that spread activation. These units are assumed to perform simple computations, and the output is based on a nonlinear function of the input. The complexity of the model lies in the "architecture" that is created by layers of units and the patterns of interconnections among them. In this model, knowledge is stored in a set of connection weights between units, based on activations. Retrieval is achieved by reproducing the series of activations from the storage phase (Smith, 1996).

This theory has primarily been applied to memory and perception, but has the potential for use in other areas (e.g., social psychology; Smith, 1996). In fact, the figures presented to illustrate the connectionist model (e.g., Smith, 1996, Figure 1, p. 895) are similar in complexity to those used in CAPS (Mischel \& Shoda, 1995, Figure 4, p. 254) and knowledge-and-appraisal personality architecture (KAPA; Cervone, 2004, Figure 2, p. 189). However, for the purpose of this study, I will focus on Cervone's KAPA model.

\section{Knowledge-and-Appraisal Personality Architecture}

Personality architecture has historically been analyzed both at the general level, trying to conceptualize the nature of humans, and also at an individual level, where analyses focus on explaining patterns of personality function (Cervone, 2005). In an attempt to integrate these perspectives, Cervone (2004) built on the work of Mischel and Shoda (1995), taking personality measurement to the idiographic level in an attempt to specify the personality variables that would fit into the CAPS framework. In his article, Cervone proposes the knowledge-and-appraisal personality architecture (KAPA), in which personality is a function of both knowledge and appraisals, the two qualitatively different aspects of cognition. He further explains that knowledge is an "enduring structural feature of personality" (p. 186), whereas appraisals are dynamic. In his model, these two features interact to influence behavior such that in emotional situations appraisals have the most impact and when the situation does not evoke strong emotional reactions, knowledge is the dominating determinant (Cervone, 2004). More specifically, the appraisal process acts as a mediator between knowledge and emotion.

Perhaps the most important feature of Cervone's model is that it provides both the mechanisms that underlie personality coherence and a method with which to identify those 
patterns. He suggests that in a given situation, only some elements of an individual's knowledge structure are activated. These patterns are believed to be stable across situations that are relevant to the same schemas. Thus, in order to understand personality, one must understand an individual's "chronically accessible knowledge," that is, that which is most frequently activated (p. 189), and those situations that are most likely to activate that knowledge.

In order to create this architecture of personality, Cervone used a unique methodology. First, he identified participants' self-relevant schemas by having them write two essays, one describing their self-relevant strengths and the other describing their self-relevant weaknesses. The most self-relevant strength and most self-relevant weakness became two of the three selfrelevant schemas used in the other steps of his study. The third self-relevant schema was identified by asking participants to fill out a bipolar attribute scale adapted from Markus's 1977 study, and then categorize those attributes according to their degree of personal importance. The attribute labeled "most important" was used as the third self-relevant schema. He also identified two common personality characteristics, one positive and one negative, that he included in the other steps of his study.

In the second step, Cervone asked participants to evaluate 80 situational phrases with respect to the importance of the situation described to each of the five schemas for that individual. From these situational phrases, he developed 80 self-efficacy items that were highly concrete, detailed descriptions of situations related to those presented in step 2. In step three, participants rated their self-efficacy on those 80 items. Following this procedure, he was able to illustrate how "situational knowledge and self-knowledge combined to foster coherent patterns of appraisal" (Cervone, 2004, p. 195). He found clusters of situations that were related to a specific schema at the idiographic level of analysis. When he aggregated those items that related across individuals to a specific attribute, he found that scores on the self-efficacy items were significantly higher for those individuals who identified that attribute as a self-relevant strength than for individuals for which that attribute was a self-relevant weakness (Cervone, 2004). This suggests that a measure of personality could be developed that would identify an individual's efficacy for specific personality attributes.

Also important to note is the ability of the KAPA model to measure personality as a locally homogeneous variable. That is, it treats personality as a construct in which the structure 
of personality is the same across individuals, but the levels vary as a function of both betweenpeople and within-people differences (Borsboom et al., 2003). 


\section{Overview of the Current Study}

The current study replicates Cervone's (2004) study, with three important changes. First, in the current study, participants were instructed to consider only work contexts for their essays, the 80 situational phrases referenced broad work contexts, and the self-efficacy items were more detailed, specific work scenarios. In contrast, in Cervone's study, participants were allowed to consider any context when writing the essays, and the situational phrases and self-efficacy items were drawn from a broad range of contexts relevant to college students (for example, 'If you're at a party where you don't know most of the people, entertain a big crowd of people by telling some jokes or stories"). Second, rather than using Markus's 1977 study as the basis for the bipolar attribute scale, the current study used items adapted from McCrae and Costa's 1987 set of bipolar attributes. Finally, in order to simplify the data entry process, participants used precoded opscan forms and a 5 point likert scale when rating the relevance of each of their assigned characteristics to the 80 situations in phase 2, rather than perform the sorting task described by Cervone (2004). According to Funder (personal communication, April 12, 2006), these two methods are approximately equivalent, but the sorting task is better if the judgments are difficult or if there are strong social desirability pressures present. In this study, there is a trade-off between simplifying the data entry process and having slightly more accurate results due to the possibility of perceived social desirability pressures in the self-ratings. The researcher felt it was preferable to use the likert rating scale and accept the possibility of slightly less accurate results.

This study was conducted in three phases. In the first phase, a set of three self-relevant schemas ${ }^{1}$ and two normative (common) schemas were identified for each participant. Using the essay writing method described by Cervone (2004), participants were asked to write one essay regarding their self-relevant strengths and one regarding their self-relevant weaknesses in a work context. Then from their writing, participants identified one positive and one negative attribute ${ }^{2}$, which became two of their three self-relevant schemas. The third self-relevant schema was identified using a bipolar attribute scale adapted from McCrae and Costa (1987). Two of the five most frequently mentioned attributes were also assigned to each participant to be used in the other phases of the study.

Like the second step described in Cervone (2004), in phase 2, participants rated the relevance of each of their five attributes to 80 situational phrases. These phrases described broad, general situations that commonly occur in a work setting. The ratings were used to 
determine which situations were perceived to be related to each of an individual's attributes. For each of the 80 situations, a self-efficacy item was generated. These items were highly concrete, detailed descriptions of specific work situations. In phase 3, participants were asked to rate their self-efficacy on these items based on how confident they were that they could succeed in the situation presented. It is these self-efficacy items that serve as the indicators of personality in this new method of personality assessment.

The purpose of phase 3 was to examine the validity of the self-efficacy items as items used to measure personality. As done by Cervone (2004), the self-efficacy ratings were "validated" through comparisons to the data collected in phases 1 and 2. In particular, I expected individuals would have higher mean self-efficacy scores on the phase 3 items that were related to the phase 2 situations that they rated as very relevant to their self-relevant strength. This was in comparison to the mean self-efficacy scores on items related to those situations that they believe to be less relevant to that attribute. Further, individuals should have had a lower mean selfefficacy score for those items related to situations rated as very relevant to their self-relevant weakness, compared with those items related to situations that they believed were less relevant to that attribute. 
Method

\section{$\underline{\text { Participants }}$}

Three hundred twenty-nine undergraduates from a large southeastern university (105 male, 217 female, 7 unspecified, mean age 19.7, age range 18-29) with at least six months of work experience participated in phase 1. Of these participants, 236 completed phase 2 (67 male, 165 female, 4 unspecified, mean age 19.7, age range 18-29). Two hundred fifteen participants completed phase 3; however, useable data was only obtained from 197 of them (53 male, 140 female, 4 unspecified, mean age 19.65, age range 18-29). Eighteen participants could not be matched to the phases 1 and 2 data due to erroneous or missing identification numbers and were therefore excluded from analysis.

Phase 1

Procedure. Phase 1 was completed by participants online through survey.vt.edu. First, participants completed the informed consent forms and a demographic questionnaire. Then they were asked to write two essays, one describing their personal strengths in a work context and the other describing their personal weaknesses in a work context (See Appendix A). They were instructed to write at least 150 words for each essay. After both essays were completed, they were asked to read through them and list the three attributes in each one that they believed were most self-relevant. Then they were asked to rank order each of the lists of three. Next participants were asked to rate themselves in relation to the "average person" in a work context using a 20 item bipolar attribute scale adapted from Table 3 of McCrae \& Costa (1987, p.85; See Appendix B). Each bipolar attribute was rated on an 11-point scale (1 being the anchor for the adjective on the left and 11 being the anchor for the adjective on the right, while a score of 6 would mean that that individual believed he/she was about the same as the average person). An example item follows:

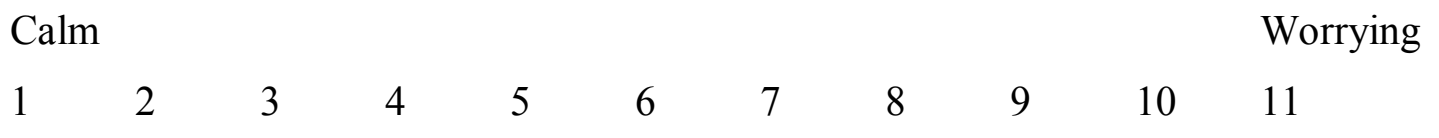

After completing the scale, participants were asked to rank those attributes on which an extreme score was reported (1-4 or 8-11) according to his/her perceived personal importance or self-relevance. Upon completion of phase 1, the participant saw the exit screen, which thanked them for their participation, requested that they write down their ID number for use in the 
following phases, and informed them that they would receive an email within one week with instructions regarding how to sign up for phase 2 .

Schema Development. The most self-relevant strength and most self-relevant weakness that were described in the essays became two of the three total self-relevant schemas used for the other phases of the study. The third self-relevant schema was selected by the participant from the list of items on the bipolar attributes scale on which the participant responded with an extreme score. The bipolar attribute scale was used for the selection of the third self-relevant attribute, rather than using the essays again, in order to insure that the selected characteristics were not one-sided. In other words, the bipolar attribute scale guaranteed that each participant considered his/her level of various characteristics.

In addition, two normative schemas from the five most frequently mentioned selfrelevant attributes were added to each participant's set of three self-relevant schemas for use in phase 2. These five attributes were ranked-ordered using the frequency distribution from most common to least common. For each participant in phase 1, the two highest ranking attributes not already identified as part of the participant's self-schema were chosen as the fourth and fifth schemas used in phase 2. For example, if the five most common responses given were ordered as organized, extraverted, assertive, determined, and reliable and participant 1 identified extraverted, assertive, and procrastinating as his/her self-relevant schemas, the two additional attributes for this participant were organized and determined. Upon completion of phase 1, the researcher and research assistant compiled the lists of self-relevant and normative schemas for each participant.

$\underline{\text { Phase } 2}$

Procedure. Phase 2 was conducted during a two hour session in the lab. For each participant, the researcher and research assistant created a list of the five schemas based on the phase 1 results. Each schema was printed on a small strip of paper, and then each set of 5 was placed in a sealed envelope. Each envelope used only the ID number given in phase 1 for participant identification. When the participant reported to the lab for the start of phase 2 , he/she was instructed to get his/her envelope and leave it sealed until the instructions had been read. The researcher or research assistant then read the instructions and answered any questions. Then the participant was given one of the schemas from the envelope, the pre-coded opscan form matching that characteristic, and a list of 80 brief descriptions of broad, general work situations 
(e.g., "Leading group meetings"). These situational phrases were adapted from a measure created by Chang (unpublished measure); with additional situations generated through brainstorming lists of common work situations by 30 students in an Introductory Psychology Recitation class (See Appendix C). Participants were given these instructions:

The following is a list of 80 situational phrases. Please use the scale presented below to rate the relevance of the characteristic on the paper you have been given to the situation. More specifically, how much influence do you feel this characteristic has on performance (good or bad) in the situation? For example, the characteristic "reliable" may be relevant to the situation "complete assignments on time." Fill in your answers on the scan sheet provided. When you have finished, please see me.

They rated the situations on a 5 point likert scale ranging from not relevant to very relevant. After they completed this process for each of the five schemas in their envelope, they were thanked again for their participation and informed that they would receive another email within one week with instructions for accessing the online survey for phase 3 .

Phase 3

Procedure. In phase 3, participants were asked to complete an 80 item self-efficacy measure (see Appendix D) online using survey.vt.edu. Upon completion, participants were thanked once more for taking part in this study. They also received a reminder that they could contact the researcher with questions or for the results of the study.

Self-Efficacy Scale. For each of the 80 situational phrases from phase 2, a self-efficacy item was developed that described a more detailed common work related scenario. Each respondent rated each work situation using a Confidence scale (Bandura, in press) ranging from "cannot do at all" (0) to "moderately can do" (50) to "highly certain can do" (100). For example, an item looked like the following:

Rate your degree of confidence that you could successfully complete the task described by recording a number from 0 to 100 using the scale given below:

$\begin{array}{lllllllllll}0 & 10 & 20 & 30 & 40 & 50 & 60 & 70 & 80 & 90 & 100\end{array}$

Cannot Moderately Highly certain


If I were assigned to lead a meeting of a group of people that had never met before, I would be able to lead the group in introductions and discussion of a plan of action for a newly assigned project. 


\section{Results}

\section{Modified Replication of Cervone (2004)}

In phase 1, participants were asked to write personal essays regarding their strengths and weaknesses in a work context. They then selected the most self-relevant strength and most selfrelevant weakness. These characteristics became two of the three schematic attributes for each participant. The third self-relevant attribute was selected by participants from the bipolar attributes scale that they completed in phase 1. Overwhelmingly, participants chose attributes at the positive end of the pole. These were coded as bipolar strengths. For those individuals who chose a negative attribute, it was coded as a bipolar weakness. In sum, a participant's responses were used by the researcher to create a set of three schematic attributes for that individual. The researcher and research assistant took great care in ensuring that participants were assigned three distinct characteristics. For example, if an individual listed dependable, organized, and friendly as his top three self-relevant strengths, and selected reliable as his bipolar attribute, then organized (choice 2) was assigned as his self-relevant strength and reliable was used as his bipolar attribute.

As in Cervone (2004), the characteristics given by participants varied dramatically, even when limited to the work context. Some people used broad dispositional terms such as "agreeable," "sociable," "lazy," and "determined," while others described more specific selfknowledge including "confident in the system," "not communicating effectively," "unable to work long hours," and "poor team player" (see Table 1). The differences in these individuals' perceptions reinforce the need for idiographic analysis of personality because trait/dispositional measures cannot capture meaningful differences in personality perceptions.

In addition to the three schematic attributes, each participant was assigned two of the five most frequently mentioned characteristics as normative attributes to rate in phase 2 . These attributes were Hard Working, Gregariousness, Dependability, Good Natured, and Organized (see Table 1). By including normative characteristics for each participant to rate, conclusions regarding whether an individual must possess a given characteristic in order to be considered an expert, or if "expert knowledge" can be obtained merely from exposure to common characteristics (i.e. those rated as the five most common characteristics in phase 1). If ratings of individuals that do not possess the characteristic are equivalent to those of the individuals that do 
possess the characteristic, then for the most common characteristics, phase 1 would not be necessary.

Frequency Distribution. The coding of the phase 1 data was done in two steps. In preparation for phase 2, each self-relevant characteristic given in phase 1 was evaluated in relation to those previously mentioned and similar terms were coded under the same number. For example, one respondent listed "reliable" as his/her self-relevant strength and a second listed “dependable." These characteristics were combined into one category that I called "dependability." During the coding of phase 1, in preparation for phase 2, the researcher and research assistant only combined direct synonyms and antonyms yielding a total of 101 characteristics (see Table 1). These combinations did not have any affect on the idiographic analysis, however, as the data for this analysis was distinguished only by type of characteristic (self-relevant strength, self-relevant weakness, bipolar strength, and bipolar weakness).

Analysis of Situational Relevance. In phase 2, participants rated the relevance of each of their five assigned attributes from phase 1 to 80 situational phrases, resulting in 400 total ratings for each participant. These ratings were used to form detailed representations of each individual's beliefs regarding the relevance of his/her specific attributes to work situations. Participant 411228, for example, listed time management (self-relevant strength), perfectionist (self-relevant weakness), and organized (bipolar strength) as her self-relevant characteristics (see figure 1). In phase 2, she rated the relevance of being an organized person to performance in work situations. Three of the situations that she believed were relevant were representative of the group of people that rated the relevance of being organized on the work situations (based on the nomothetic analysis conducted, see below). However, her responses were also idiosyncratic. For example, one situation that logically seems illustrative of an organized person-working on a project that is very detailed and precise - was not rated as relevant to this attribute by this individual.

Further, similar to Cervone (2004), there were several participants who chose the same self-relevant strength, but rated that characteristic as relevant to very different situations. For example, participants 49 and 63 (see figure 2) both believed that soft hearted is a self-relevant strength, but the only situation that they agreed the attribute is relevant to is "helping to create an atmosphere of comfort in the workplace." Participant 49 tended to relate soft heartedness to providing service or assistance to others at work, while participant 63 related the attribute to 
resolving conflicts. This suggests that this attribute means different things to different people (Cervone, 2004). This type of between subjects variance is treated as error by trait theorists, but in reality, it provides useful information regarding the complexity of human personality.

More importantly, there are several instances where participants rated the same attribute as relevant to a nearly identical group of situations. For example, individuals 14 and 39 (see figure 3) both chose dependability as a self-relevant strength. Each rated the characteristic to be relevant to six situations, five of which were the same for both participants. It is this commonality among individuals' self- and situational knowledge that is the key to moving forward to a nomothetic level of analysis.

Analysis of Self-Efficacy Ratings. During phase 3, participants rated their self-efficacy for succeeding in 80 concrete, detailed work situations that were directly related to the 80 situational phrases rated in phase 2. Relationships were expected between the self-efficacy appraisals in phase 3, the ratings of situational knowledge (relevance) in phase 2 , and the selfknowledge (self-relevant characteristics) reported in phase 1. Specifically, self-efficacy appraisals should vary as a function of both self-knowledge (whether the characteristic was schematic or normative) and situational knowledge (ratings of relevance of characteristics to situations) such that for those characteristics rated as either a self-relevant strength or a bipolar strength, the mean self-efficacy appraisal should be highest for those items related to phase 2 situations rated as very relevant and lowest for those items related to situations rated as slightly relevant (ratings of not relevant are not included in this analysis).

In contrast, for those characteristics rated as either a self-relevant weakness or a bipolar weakness, the mean self-efficacy appraisal should be lowest for those items related to the situations rated as very relevant and highest for those situations rated as slightly relevant (again, ratings of not relevant were not included in this analysis). For each participant, the mean selfefficacy appraisals were calculated for each of the 5 characteristics for each level of situational relevance (slightly relevant, moderately relevant, reasonably relevant, and very relevant). Put another way, for each characteristic rated by each participant, the self-efficacy ratings (phase 3) were averaged according to the level of situational relevance (phase 2). This resulted in a total of 5 averages for each participant on each type of characteristic (phase 1). Then, the average of these mean self-efficacy appraisals was calculated across all participants for each level of situational relevance. 
Figure 4 depicts the mean self-efficacy appraisals for the schematic attributes broken down by type of attribute. The types are self-relevant strength, self-relevant weakness, and bipolar strength. Those individuals that chose a bipolar attribute from the weakness side of the pole were excluded from this analysis because of the very small $n$ size $(n=12)$ compared to the other groups (self-relevant strength $n=242$, self-relevant weakness $n=242$, bipolar strength $n=$ 228). This figure shows that the results follow the expected pattern of efficacy appraisals. The mean self-efficacy ratings for both self-relevant strengths and bipolar strengths increased as level of situational relevance increased, with the level "very relevant" showing the highest mean selfefficacy ratings. At the same time, the mean self-efficacy rating for the self-relevant weakness decreased as level of situational relevance increased, such that the level of "very relevant" is associated with the lowest mean self-efficacy rating. Table 4 shows the effect size between each level of relevance, as well as the overall effect size between slightly relevant and very relevant for each type of attribute. Participants exhibited higher levels of self-efficacy for those items that they believed were very strongly related to their self-relevant strengths (effect size $r=0.1861$ ) and bipolar strengths (effect size $r=0.1255$ ) than for those items that were less strongly related to these characteristics. Further, participants showed lower levels of self-efficacy for those items that they believed were most strongly related to their perceived weakness (effect size $r=$ 0.0778).

On the other hand, I did not expect to see any particular pattern of self-efficacy appraisals on the normative attributes. These attributes were assigned in order to verify that the patterns of responses found with the schematic attributes are unique to those characteristics that individuals perceive as self-relevant. It was believed that participants would not score particularly high or low on self-efficacy appraisals for characteristics that were assigned normatively as the most common characteristics. Figure 5 presents the mean self-efficacy appraisals for three of the five normative characteristics. Good natured and organized were not included in this analysis due to their low $n$ sizes (good natured $n=25$, organized $n=6$ ). Table 5 shows the effect size between each level of relevance, as well as the overall effect size between slightly relevant and very relevant for each attribute. While dependability shows the same trend as the self-relevant strength and the bipolar strength (effect size $r=0.2297)$ and the effect size for hard working $(r=$ 0.1420 ) is similar to those of the strengths, the overlapping standard error of the mean bars in figure 5 suggest that the differences between levels of relevance are not as strong as those for the 
self-relevant strength and the bipolar strength (see figure 4). It is likely that dependability and hard working perform similarly to the schematic strengths due to the perceived social desirability pressures when responding to self-efficacy items regarding work (see faking and social desirability below). The results for gregariousness provide support for this idea (effect size $\mathrm{r}=$ 0.0537). In the workplace, being gregarious is not perceived as being as strongly socially desirable as being hard working or dependable (Barrick \& Mount, 1991).

Nomothetic Analyses

Idiographic analyses provide a richer description of individuals than nomothetic analyses. However, when the goal is to describe and compare personalities among different people, the idiographic approach is cumbersome due to the rich nature of the data. Therefore, in the second step of analyses, the data were analyzed at the nomothetic level in order to facilitate the development of a common metric useful for comparing individuals.

Coding of phase 1. As previously mentioned, the coding of phase 1 took place in two steps. The first step, described earlier, resulted in a list of 101 characteristics (see Table 1). In order to accommodate the nomothetic analysis, the researcher and research assistant further condensed the 101 characteristics by forming slightly broader categories using Goldberg's (1990) revised synonym clusters as a guide. For example, Goldberg includes the terms "considerate, kind, sympathetic, trustful, understanding" in the cluster "Empathy" (p. 1224). So, these terms were combined to form one characteristic called "empathy." Agreement between the researcher and research assistant was a necessary condition for combining characteristics. Further, characteristics rated by fewer than 3 participants were excluded. This left a total of 42 characteristics for analysis (see Table 2).

Nomothetic Agreement of Situational Relevance. As a whole, participants grouped 14-15 situations on average into each relevance level (slightly, moderately, reasonably, very) using the 5 point likert scale. However, there was quite a bit of variance across subjects, with some participants rating their characteristic as relevant to $70+$ situations and others not rating their characteristic as relevant to any of the situations. Specifically, there were 25 cases where no situations were rated as relevant to the characteristic and 7 instances where $70+$ situations were rated as relevant to the characteristic. There is a possibility that in some of these cases, the participant did not take the rating task seriously. Closer inspection reveals a pattern of extreme responding for only two individuals. These individuals chose to rate almost all situations as 
relevant to their characteristics, rather than differentiate between the situations. However, it is unlikely that these two individuals have a significant impact on distorting the results of the analyses.

The number of situations rated as very relevant also varied as a function of the characteristic being rated. Those characteristics that are traditionally linked to performance in a work context (i.e. facets of Conscientiousness) had the most situations rated as relevant, including hard working, dependability, self-motivated, and dedicated. Other characteristics that relate to interacting with others, such as gregariousness, amiable, and spirit, also had high numbers of situations rated as relevant. There were several characteristics for which no situation was rated as relevant including cautious, curious, and emotional.

In phase 2, the nomothetic characteristics were included to assess whether an individual had to possess a given characteristic in order to achieve "expert knowledge," or if mere exposure to common characteristics, such as those five characteristics rated as most frequently in the current study, could also yield "expert knowledge." If individuals possessing the characteristic and those individuals that rated the characteristic normatively do indeed rate the same situations as relevant, it would suggest that "expert knowledge" of common characteristics can be achieved by individuals that do not possess the characteristic. If this is the case, then phase 1 would not need to be included when only assessing the relevance of situations to common characteristics. The agreement between the individuals possessing the characteristics and those individuals that rated the characteristic normatively was approximately $70 \%$. Table 3 includes the number of items rated relevant on average by individuals possessing the characteristic and those individuals that rated the characteristic normatively. Further, table 3 includes the number of situations that both groups agreed were relevant to the characteristic and the percentage agreement between those that overlapped and those that were rated as relevant to the group possessing the characteristic. Situations were considered relevant if the average rating was 4.5 or higher (between reasonably and very relevant). The main difference between the ratings of the schematic raters and the nomothetic raters is that the nomothetic group rated more situations as relevant to each characteristic. These results suggest that "expert knowledge" cannot be gained simply through exposure to common characteristics. Although the nomothetic raters did show strong agreement with the situations rated as relevant by the schematic group, they believed that 
many more situations were relevant than the schematic group. Therefore, I must conclude that phase 1 is necessary for all characteristics.

Top Down vs. Bottom Up Assessment Strategies. The Big Five approach to personality assessment is an example of a top down strategy. Individuals are asked to rate themselves on a group of items, then factor analysis techniques are used to group items on which individuals respond in a similar fashion. Then the decisions for naming these groups are done by the researchers' looking at the items and attempting to find a common thread. However, it is likely that individual differences in the perceptions of the items cause people to look the same on the surface (ratings), and yet have very different self-perceptions. If, instead, a bottom-up approach to personality assessment, such as the one used in this study, is employed, these important differences are readily observable. Figure 6 provides evidence for this point. On the surface, using a top down assessment, it would appear that these individuals perceive themselves as being similar on a characteristic that may be called leadership, based on the researcher's examination of the associated items. However, this bottom up study illustrates the real differences in selfperception between the individuals in figure 6. Participant 440224 believes his self-relevant strength is gregariousness, while participant 253229 views her self-relevant weakness is bossy. Both participants rated the seven situations in figure 6 to be relevant to their respective characteristics, and they also had similar self-efficacy ratings for the items related to those situations. Therefore, although they rate themselves similarly on this group of items, they believe that the situations related to these items are indicative of two very different characteristics. It is also interesting to note that one characteristic is considered to be a strength, while the other is viewed as a weakness. These important differences would not be apparent using top down assessments.

Specific analysis of the characteristic "gregariousness." Beyond Cervone's (2004) original article, the ultimate purpose of the line of research instigated in the current study is to use Cervone's theory of cognitive architecture as the foundation for developing a "situationallysensitive" nomothetic measure of personality. It is a simple matter to establish, for example, those situations that were agreed by raters to be relevant (e.g., using an average relevance rating above 4.50) to a characteristic. Then the self-efficacy items written for those relevant situations can be considered indicators of the characteristic. The characteristic gregariousness was rated by a total of 151 raters (19 strength, 113 normative, and 19 weakness). These individuals agreed 
(using the 4.5 or above criterion) that the six situations listed in table 6 were relevant to gregariousness. Figure 7 presents the mean self-efficacy appraisals. Those individuals who rated gregariousness as a strength scored highest on the self-efficacy items related to relevant gregariousness situations, while those that rated it as a weakness scored lowest (effect size $r=$ $0.3391, \mathrm{p}=0.03282)$. The normative raters scored in between the strength raters and the weakness raters.

This analysis of gregariousness provides a brief insight into the future of this research program. The ultimate goal of this line of research is to develop a comprehensive "structure of work" with associated self-efficacy items that reflect underlying personological characters related to success or failure in each situation. Once this "work situation x characteristics" matrix is developed, the nomothetic assessment of personality can reflect as few or as many of the relevant work situations as needed. For example, if an overall assessment of gregariousness is desired, then all work situations related to gregariousness can be used to measure the characteristic (as was done in figure 7). However, if a situation is not deemed relevant to the assessment of the personality, for whatever reason(s), then this situation can be dropped. This allows the measure of gregariousness to be tailored to the needs of the situation. For example, perhaps the situation "working on a sales floor assisting customers" is not relevant to what an applicant will do for an organization. As such, that situation can be dropped from the assessment of gregariousness in order to reflect a measure that is more directly relevant to the work situations encountered by the applicant. The expectation is that such a personality assessment strategy will produce a measure of personality that more closely responds to how personality is represented within the person, thereby producing greater construct validity in the assessment of personality. This will ultimately produce greater predictive accuracy. 


\section{Discussion}

\section{Discussion of Idiographic Analysis}

Combined, the findings suggest three things. First, in phase 1, participants were able to identify self-relevant attributes in the context of work. The use of personal essays provides insight beyond using Big Five techniques to assess personality, into how each individual perceives him/herself. Further, the frequency of responses using similar characteristics provides evidence suggesting which characteristics are most frequently associated with performance at work. It has been shown that conscientiousness is the most predictive of the Big Five for job performance (Barrick \& Mount, 1991), but the technique employed in this study illustrates more specifically which facet level characteristics are globally believed to be important in work contexts.

Second, individuals are able to rate the relevance of each self-relevant attribute to work situations. These ratings are accurate to self-perceptions because they correspond to how efficacious the participants perceive themselves to be in those situations (see figure 4). This provides evidence for the construct validity of the self-efficacy items. However, much more validation is needed. And third, while there are several instances of idiosyncrasy in the data (see figure 2), there are also many commonalities in both the characteristics believed to be selfrelevant and the situations to which those characteristics are relevant. This finding opens up the possibility of using an alternative strategy to develop a nomothetic measure of personality using idiographic methods. Taken together, these results show that careful consideration must be given when developing a nomothetic measure in order to minimize the effects of the between subjects differences in perception of characteristic meaning. Specifically, the new measure should focus on measuring those characteristics for which agreement on perception of meaning is high, rather than neglect potential differences in perception of meaning and use only reported level of characteristics as trait theories do currently.

\section{Discussion of Nomothetic Analysis}

The purpose of the current study was to replicate Cervone's (2004) study in the context of work. For the most part, the results of the current study replicate the findings from Cervone (2004). Most importantly, the results of both studies suggest that there exist both idiosyncrasies and commonalities between people. Cervone's method of studying personality is useful because it allows, using idiographic data, for the examination of not only the idiosyncrasies, but also the 
commonalities that are evident. Therefore, this method enables researchers to employ bottom up strategies to develop measures of personality that do not have the limitations of measures developed by using top down strategies: treating within subjects variance as error and being unable to detect surface differences in personality (see figure 6). 


\section{General Discussion}

Cervone (2004) identifies six classes of social-cognitive constructs by distinguishing between knowledge and appraisal directions of fit and intentional states. Specifically, he makes the distinction between knowledge, having a mind-to-world direction of fit, and appraisal, having a world-to-mind direction of fit. Knowledge reflects what is known by an individual about the world (e.g., "a Ph.D. is required in order to be a professor at a university”), while appraisals are intentions to make a future state happen that matches the individual's current mental content (e.g., "my goal is to earn a Ph.D."). He also makes a distinction between different intentional states, including beliefs, aims, and evaluative standards. Beliefs are defined as having mind-toworld direction of fit about an entity, while aims are world-to-mind goals to create or maintain a desired state. Evaluative standards are not easily classified using direction of fit distinctions. Rather, they are the standards by which an individual evaluates him/herself and the world.

Taken together, these distinctions create the six classes of social-cognitive constructs (see Cervone, 2004, Figure 9, p. 198). Cervone proposes that in the KAPA model, these classes work together to create personality. In the current study, the focus was on measuring knowledge and appraisal of beliefs. In future studies, it may be useful to measure knowledge and appraisal evaluative standards and aims in order to obtain a better understanding of the personality processes.

In the KAPA view of personality dispositions, there are two important features. First, dispositions are descriptions, not explanations for behavior. Second, they are social constructions created by investigators in order to summarize between person differences (Cervone, 2004). Cervone believes that situation-response frameworks that are defined using nomothetic data are unable to adequately differentiate each individual because these individuals vary idiosyncratically on attributes, responses, and situations considered relevant. Figure 6 illustrates this concern. People may have a similar outcome on a personality measure, yet differ substantially on the underlying construct of interest due to differences in perceptions of situational relevance. Using KAPA, a bottom up method of personality assessment, these idiosyncrasies are readily observed and can be dealt with. Although Cervone focuses on idiosyncrasies, there are many more commonalities between people's evaluations of characteristics and relevant situations. These commonalities are the foundation for a new method of personality assessment that will not be limited by treating all idiosyncrasies as error. 


\section{Limitations}

Weaknesses of Method. Although this method overcomes many of the limitations of the dispositional approach to personality assessment, there are still weaknesses that must be addressed. First, this method requires large numbers of participants to complete several phases during period of about a month. Since the data must be collected longitudinally, there is less anonymity, as well as high rates of attrition as participants drop out without completing all phases. The rate of attrition in this study, for example, was over $40 \%$. Second, the methods for statistical analyses are much less sophisticated than those used by dispositional researchers. Common inferential techniques, such as analysis of variance could not be used because of frequent dependencies in the data and considerable differences in sample sizes between groups of raters for each characteristic by type of rating. Instead, this study relied on effect sizes in order to show differences both between and within subjects. There is not yet an agreed upon method for analyzing idiographic data. However, new statistical techniques have been employed in several situations, including improving weather predictions, which provides evidence for alternative statistics that could be applied to this type of data (Carretero, 2002).

Faking and Self-Efficacy. According to Bandura (in press), the best way to minimize response bias due to social desirability pressures is to allow self-efficacy judgments to be recorded privately and anonymously. Privacy can be achieved in both a study such as this and in work situations when individuals are allowed to complete measures without others present, however, anonymity is just not feasible. Therefore, an issue of this method of personality assessment is the potential for individuals to fake in order to increase the likelihood of being hired. Impression management is affected by two processes, impression motivation and impression construction (Leary \& Kowalski, 1990). Impression motivation involves the desire to be perceived a certain way by others. When an individual is applying for a job, it is likely that person will want to create a certain impression in the person(s) making the hiring decision. Therefore, impression motivation will drive the individual to depict him/herself in a favorable light on the application. Impression construction is the second part of impression management. Once an individual is motivated to create a certain impression in another, the individual may change his/her behaviors in order to manifest this impression. When both impression motivation and impression construction work together, the individual may be inclined to fake on personality tests. This phenomenon will probably lead to some over-representation of desired characteristics 
and under-representation of undesirable ones. For example, the individual may be $50 \%$ confident in his/her ability to perform well under pressure (a desired ability), but state that he/she is $70 \%$ confident. The degree to which an individual over- or under-states his/her confidence on an item will be related to the perception of the importance of the job to the individual (Leary $\&$ Kowalski, 1990). Therefore, on applications for jobs that the individual desires strongly, the amount of distortion will be higher than for those jobs that the individual doesn't desire as much.

As stated previously, there is little disagreement regarding the existence of faking on personality measures. The disagreement lies in the effect faking has on the utility of these measures in predicting job performance. The same arguments apply to the measure developed using the technique outlined in this study. Bandura (in press) asserts that researchers have questioned whether recording a level of self-efficacy on an item affects an individual's behavior in the situation. For example, does rating self-efficacy for playing the piano at $100 \%$ create piano playing ability in the individual? Findings have shown that despite prior self-efficacy judgments, an individual's level of motivation, affective reactions, and performance are the same. This suggests that regardless of self-efficacy ratings made by an individual, there will be no need for that person to behave differently in order to lessen the gap between self-perception and a given self-efficacy rating. In other words, piano playing ability will not change. Faking on these measures could lead to decreased predictive accuracy when people are differentially inclined to fake. On the other hand, I believe that this new strategy of personality assessment will surpass traditional personality measures in predicting job performance, so that even with slight decreases in predictive accuracy due to faking, the amount of variance in job performance captured by this measure should be greater than that accounted for by the Big Five. Future studies will need to assess the effect faking has on the predictive utility of the new measure. 


\section{Conclusion}

This study successfully replicates Cervone's (2004) study, specific to a work context. Findings show that the method employed in both studies is useful in capturing idiosyncrasies in personality, but that there exist several commonalities in personality that can be exploited in order to create a nomothetic measure of personality that will be better able to predict job performance than traditional dispositional personality assessments (e.g., Big Five). Judgments and perceptions of the self are central in the everyday functioning of every individual. Therefore, it is crucial that assessments of personality incorporate these knowledges and beliefs (Bandura, in press). The method for measuring personality described in this study integrates both self-perception and perception of the world in an attempt to fully understand an individual's personality. Then this study relies on commonalities of self-perception and perception of the world in order to assess people nomothetically. The line of research instigated in this study can be used to create a nomothetic assessment of personality, based on idiographic data, without the limitations of traditional dispositional assessment strategies. 


\section{References}

Bandura, A. (in press). Guide for constructing self-efficacy scales. In Pajares, F., \& Urdan, T. (Eds.) Adolescence and education, Vol. 4: Self-efficacy beliefs of adolescents.

Greenwich, CT: Information Age Publishing.

Barrick, M. R. \& Mount, M. K. (1991). The Big Five Personality Dimensions and Job Performance: A Meta-Analysis. Personnel Psychology, 44, 1-26.

Berry, L. M. (2003). Employee Selection. United States: Thompson/Wadsworth.

Bing, M.N., Whanger, J.C., Davison, H.K., \& VanHook, J.B. (2004). Incremental Validity of the Frame-of-Reference Effect in Personality Scale Scores: A Replication and Extension. Journal of Applied Psychology, 89, 150-157.

Bollen, E. \& Wojciechowski, F.L. (2004). Anorexia Nervosa Subtypes and the Big Five Personality Factors. European Eating Disorders Review, 12, 117-121.

Bono, J.E. \& Judge, T.A. (2004). Personality and Transformational and Transactional Leadership: A Meta-Analysis. Journal of Applied Psychology, 89, 901-910.

Borsboom, D., Mellenbergh, G.J., \& van Heerden, J. (2003). The Theoretical Status of Latent Variables. Psychological Review, 100, 203-219.

Bradley, K.M. (2003). Personality Test Validation Research: Present-Employee and Job Applicant Samples. Virginia Tech Electronic Theses and Dissertations. Retrieved October 6, 2005 from http://scholar.lib.vt.edu/theses/

Buchanan, T., Johnson, J.A. \& Goldberg, L.R. (2005). Implementing a Five-Factor Personality Inventory for Use on the Internet. European Journal of Psychological Assessment, 21, 115-127.

Carretero, R. (2002). Nonlinear Dynamical Systems at SDSU. Retrieved April 17, 2006 from http://nlds.sdsu.edu/

Cattell, R.B. (1945). The Description of Personality: Principles and Findings in a Factor Analysis. The American Journal of Psychology, 58, 69-90.

Cattell, R.B. (1966). The Scientific Analysis of Personality. Chicago: Aldine.

Cervone, D. (2004). The Architecture of Personality. Psychological Review, 111, 183-204.

Cervone, D. (2005). Personality Architecture: Within-Person Structures and Processes. Annual Review of Psychology, 56, 423-452. 
Cervone, D. \& Shoda, Y. (1999). Social-Cognitive Theories and the Coherence of Personality. In D. Cervone \& Y. Shoda (Eds.), The Coherence of Personality: Social-Cognitive Bases of Consistency, Variability, and Organization (pp. 3-33). New York: The Guilford Press.

Chang, W.Y. (unpublished measure).

Costa, P.T.Jr. \& McCrae, R.R. (1995). Primary Traits of Eysenck's P-E-N System: Three- and Five-Factor Solutions. Journal of Personality and Social Psychology, 69, 308-317.

Digman, J.M. (1996). The Curious History of the Five-Factor Model. In J.S. Wiggins (Ed.), The Five-Factor Model of Personality: Theoretical Perspectives (pp. 1-20). New York: The Guilford Press.

Duijsens, I.J. \& Diekstra, R.F.W. (1996). DSM-III-R and ICD-10 Personality Disorders and Their Relationship with the Big Five Dimensions of Personality. Personality and Individual Differences, 21, 119-133.

Dwight, S. A., Wolf, P. P., and Golden, J. H. (2002). Metatraits: enhancing criterion-related validity through the assessment of traitedness. Journal of Applied Social Psychology, 32, 2202-2212.

Friedman, H.S. \& Schustack, M.W. (2006). Personality: Classic Theories and Modern Research $\left(3^{\text {rd }}\right.$ Ed.). Boston: Pearson.

Funder, D.C. (2001). Personality. Annual Review of Psychology, 52, 197-221.

Furnham, A., Petrides, K.V., \& Jackson, C.J. (2002). Do Personality Factors Predict Job Satisfaction? Personality and Individual Differences, 33, 1325-1342.

Goldberg, L.R. (1990). An Alternative "Description of Personality". The Big-Five Factor Structure. Journal of Personality and Social Psychology, 59, 1216-1229.

Goldberg, L.R. (1999). A Broad-Bandwidth, Public-Domain, Personality Inventory Measuring the Lower-Level Facets of Several Five-Factor Models. In I. Mervielde, I. Deary, F. De Fruyt, \& F. Ostendorf(Eds.), Personality Psychology in Europe, Vol. 7. (pp. 7-28). Tilburg, The Netherlands: Tilburg University Press.

Guion, R.M. \& Gottier, R.F. (1965). Validity of Personality Measures in Personnel Selection. Personnel Psychology, 18, 135-164.

Hough, L.M., Eaton, N.K., Dunnette, M.D., Kamp, J.D., \& McCloy, R.A. (1990). CriterionRelated Validities of Personality Constructs and the Effect of Response Distortion on Those Validities. Journal of Applied Psychology, 75, 581-595. 
Hui, M. \& Yongxin, L. (2004). A Research on the Relationship of the Big-Five Personality and Leadership Effectiveness. Psychological Science (China), 27, 611-614.

Hurtz, G.M., \& Donovan, J.J. (2000). Personality and Job Performance: The Big Five Revisited. Journal of Applied Psychology, 85, 869-879.

Judge, T.A., Heller, D., \& Mount, M.K. (2002). Five-Factor Model of Personality and Job Satisfaction: A Meta-Analysis. Journal of Applied Psychology, 87, 530-541.

Leary, M.R. \& Kowalski, R.M. (1990). Impression Management: A Literature Review and TwoComponent Model. Psychological Bulletin, 107, 34-47.

Markus, H. (1977). Self-Schemata and Processing Information About the Self. Journal of Personality and Social Psychology, 35, 63-78.

McCrae, R.R. \& Costa, P.T.Jr. (1985). Updating Norman's “Adequate Taxonomy”: Intelligence and Personality Dimensions in Natural Language and in Questionnaires. Journal of Personality and Social Psychology, 49, 710-721.

McCrae, R.R. \& Costa, P.T. Jr. (1987). Validation of the Five-Factor Model of Personality Across Instruments and Observers. Journal of Personality and Social Psychology, 52, 81-90.

McCrae, R.R. \& Costa, P.T.Jr. (1996). Toward a New Generation of Personality Theories: Theoretical Contexts for the Five-Factor Model. In J.S. Wiggins (Ed.), The Five-Factor Model of Personality: Theoretical Perspectives (pp. 51-87). New York: The Guilford Press.

Mendoza-Denton, R., Ayduk, O., Mischel, W., Shoda, Y., \& Testa, A. (2001). Person X Situation Interactionism in Self-Encoding (I Am...When...): Implications for Affect Regulation and Social Information Processing. Journal of Personality and Social Psychology, 80, 553-554.

Mendoza-Denton, R., Shoda, Y., Ayduk, O., \& Mischel, W. (1999). Applying Cognitive Affective Processing System (CAPS) Theory to Cultural Differences in Social Behavior. In Lonner, W.J. \& Dinnel, D.L. (Eds.) Merging Past, Present and Future in CrossCultural Psychology: Selected Papers from the Fourteenth International Congress of the International Association for Cross-Cultural Psychology (pp. 205-217). Lisse, Netherlands: Swets \& Zeitlinger Publishers.

Mischel, W. (1968). Personality and Assessment. New York: John Wiley and Sons, Inc. 
Mischel, W. (1973). Toward a Cognitive Social Learning Reconceptualization of Personality. Psychological Review, 80, 252-283.

Mischel, W. (1979). On the Interface of Cognition and Personality: Beyond the Person-Situation Debate. American Psychologist, 34, 740-754.

Mischel, W. (2004). Toward an Integrative Science of the Person. Annual Review of Psychology, 55, 1-22.

Mischel, W. \& Ayduk, O. (2002). Self-Regulation in a Cognitive-Affective Personality System: Attentional Control in the Service of the Self. Self \& Identity, 1, 113-120.

Mischel, W. \& Ayduk, O. (2004). Willpower in a Cognitive-Affective Processing System: The Dynamics of Delay of Gratification. In Baumeister, R.F. \& Vohs, K.D. (Eds) Handbook of Self-Regulation: Research, Theory, and Applications (pp.99-129). New York: Guilford Press.

Mischel, W. \& Shoda, Y. (1995). A Cognitive-Affective System Theory of Personality: Reconceptualizing Situations, Dispositions, Dynamics, and Invariance in Personality Structure. Psychological Review, 102, 246-268.

Motowidlo, S.J., Borman, W.C., \& Schmit, M.J. (1997). A Theory of Individual Differences in Task and Contextual Performance. Human Performance, 10, 71-83.

Mueller-Hanson, R., Heggestad, E.D., \& Thornton, G.C. III. (2003). Faking and Selection: Considering the Use of Personality from Select-In and Select-Out Perspectives. Journal of Applied Psychology, 88, 348-355.

Nicholson, R.A., \& Hogan, R. (1990). The Construct Validity of Social Desirability. American Psychologist, 45, 290-292.

Norman, W.T. (1963). Toward an Adequate Taxonomy of Personality Attributes: Replicated Factor Structure in Peer Nomination Personality Ratings. Journal of Abnormal and Social Psychology, 66, 574-583.

Ones, D.S., Viswesvaran, C., \& Reiss, A.D. (1996). Role of Social Desirability in Personality Testing for Personnel Selection: The Red Herring. Journal of Applied Psychology, 81, 660-679.

Raymark, P.H., Schmit, M.J., \& Guion, R.M. (1997). Identifying Potentially Useful Personality Constructs for Employee Selection. Personnel Psychology, 50, 723-736. 
Rosse, J.G., Stecher, M.D., Miller, J.L., \& Levin, R.A. (1998). The Impact of Response Distortion on Preemployment Personality Testing and Hiring Decisions. Journal of Applied Psychology, 83, 634-644.

Salgado, J.F. (1997). The Five Factor Model of Personality and Job Performance in the European Community. Journal of Applied Psychology, 82, 30-43.

Schmidt, F.L. \& Hunter, J.E. (1998). The Validity and Utility of Selection Methods in Personnel Psychology: Practical and Theoretical Implications of 85 Years of Research Findings. Psychological Bulletin, 124, 262-274.

Schmit, M.J., Ryan, A.M., Stierwalt, S.L., \& Powell, A.B. (1995). Frame-of-Reference Effects on Personality Scale Scores and Criterion-Related Validity. Journal of Applied Psychology, 80, 607-620.

Shadel, W.G., Cervone, D., \& Niaura, R. (2004). Investigating the Big Five Personality Factors and Smoking: Implications for Assessment. Journal of Psychopathology and Behavioral Assessment, 26, 185-191.

Shoda, Y. \& Smith, R.E. (2004). Conceptualizing Personality as a Cognitive-Affective Processing System: A Framework for Models of Maladaptive Behavior Patterns and Change. Behavior Therapy, 35, 147-165.

Simpson, J.A. \& Gangestad, S.W. (1991). Individual Differences in Sociosexuality: Evidence for Convergent and Discriminant Validity. Journal of Personality and Social Psychology, 60, 870-883.

Skibba, J.S. \& Tan, J.A. (2004). Personality Predictors of Firefighter Job Performance and Job Satisfaction. Applied Human Resource Management Research, 9, 39-40.

Smith, E.R. (1996). What Do Connectionism and Social Psychology Offer Each Other? Journal of Personality and Social Psychology, 70, 893-912.

Srivastava, S., John, O.P., Gosling, S.D., \& Potter, J. (2003). Development of Personality in Early and Middle Adulthood: Set Like Plaster or Persistent Change? Journal of Personality and Social Psychology, 84, 1041-1053.

Tett, R.P. \& Burnett, D.D. (2003). A Personality Trait-Based Interactionist Model of Job Performance. Journal of Applied Psychology, 88, 500-517.

Tett, R. P., Jackson, D. N., and Rothstein, M. (1991). Personality measures as predictors of job performance: a meta-analytic review. Personnel Psychology, 44, 703-742. 
Theakston, J.A., Stewart, S.H., \& Dawson, M.Y. (2004). Big-Five Personality Domains Predict Drinking Motives. Personality and Individual Differences, 37, 971-984. 


\section{Appendix A}

Instructions for Phase 1 Essay Writing Task

In the space provided below, please write an essay of at least 150 words describing your personal strengths in a work context. You are encouraged to write anything that comes to mind as a personal strength at work.

In the space provided below, please write an essay of at least 150 words describing your personal weaknesses in a work context. You are encouraged to write anything that comes to mind as a personal weakness at work.

Now, please read through your first essay and list in the space provided the three personality attributes that you feel are your most self relevant strengths. Then, rank order this list of three attributes from most self relevant (1) to least self relevant (3).

Next, please read through your second essay and list in the space provided the three personality attributes that you feel are your most self relevant weaknesses. Then, rank order this list of three attributes from most self relevant (1) to least self relevant (3). 


\section{Appendix B}

Bipolar Attribute Scale

On the following pages are 20 items. Please rate yourself in relation to the average person in a work context on each item. An example item is:

\begin{tabular}{|c|c|c|c|c|c|c|c|c|c|}
\hline Calm & & & & & & & & & Worrying \\
\hline 1 & 3 & 4 & 5 & 6 & 7 & 8 & 9 & 10 & 11 \\
\hline
\end{tabular}

If you feel that you are much calmer than the average person in a work context, you would circle 1 or 2 . If you feel you worry much more than the average person in a work context, you would circle 10 or 11 . And, if you feel you are about as calm as the average person in a work context, you would circle 5,6 , or 7 . When you have finished, please proceed by reading and following the next set of instructions.

Please rank the following attributes according to there personal importance or self relevance. Rank the most important attribute as 1 . 
1. Secure

Insecure

$\begin{array}{lllllllllll}1 & 2 & 3 & 4 & 5 & 6 & 7 & 8 & 9 & 10 & 11\end{array}$

2. Quiet

Talkative

$\begin{array}{lllllllllll}1 & 2 & 3 & 4 & 5 & 6 & 7 & 8 & 9 & 10 & 11\end{array}$

3. Uncurious

Curious

$\begin{array}{lllllllllll}1 & 2 & 3 & 4 & 5 & 6 & 7 & 8 & 9 & 10 & 11\end{array}$

4. Careless

Careful

$\begin{array}{lllllllllll}1 & 2 & 3 & 4 & 5 & 6 & 7 & 8 & 9 & 10 & 11\end{array}$

5. Callous

Sympathetic

$\begin{array}{lllllllllll}1 & 2 & 3 & 4 & 5 & 6 & 7 & 8 & 9 & 10 & 11\end{array}$

6. Loner

$\begin{array}{lllllllllll}1 & 2 & 3 & 4 & 5 & 6 & 7 & 8 & 9 & 10 & 11\end{array}$

Joiner

11

Good Natured

7. Irritable

$\begin{array}{lllllllllll}1 & 2 & 3 & 4 & 5 & 6 & 7 & 8 & 9 & 10 & 11\end{array}$

8. Unadventurous

Daring

$\begin{array}{lllllllllll}1 & 2 & 3 & 4 & 5 & 6 & 7 & 8 & 9 & 10 & 11\end{array}$

9. At Ease

$\begin{array}{lllllllllll}1 & 2 & 3 & 4 & 5 & 6 & 7 & 8 & 9 & 10 & 11\end{array}$

10. Undependable

$\begin{array}{lllllllllll}1 & 2 & 3 & 4 & 5 & 6 & 7 & 8 & 9 & 10 & 11\end{array}$

11. Conforming

$\begin{array}{lllllllllll}1 & 2 & 3 & 4 & 5 & 6 & 7 & 8 & 9 & 10 & 11\end{array}$

12. Relaxed

High-Strung

$\begin{array}{lllllllllll}1 & 2 & 3 & 4 & 5 & 6 & 7 & 8 & 9 & 10 & 11\end{array}$

13. Vengeful

$\begin{array}{lllllllllll}1 & 2 & 3 & 4 & 5 & 6 & 7 & 8 & 9 & 10 & 11\end{array}$

14. Disorganized

Well Organized

$\begin{array}{lllllllllll}1 & 2 & 3 & 4 & 5 & 6 & 7 & 8 & 9 & 10 & 11\end{array}$

15. Sober

Fun Loving

$\begin{array}{lllllllllll}1 & 2 & 3 & 4 & 5 & 6 & 7 & 8 & 9 & 10 & 11\end{array}$


16. Comfortable

Self-Conscious

$\begin{array}{lllllllllll}1 & 2 & 3 & 4 & 5 & 6 & 7 & 8 & 9 & 10 & 11\end{array}$

\section{Ruthless}

$\begin{array}{rrrrrrrrrrrr}1 & 2 & 3 & 4 & 5 & 6 & 7 & 8 & 9 & 10 & 11\end{array}$

18. Lazy

$\begin{array}{lllllllll}1 & 2 & 3 & 4 & 5 & 6 & 7 & 8 & 9\end{array}$

Hard Working

19. Conservative

$\begin{array}{lllllllllll}1 & 2 & 3 & 4 & 5 & 6 & 7 & 8 & 9 & 10 & 11 \\ \text { firing } & & & & & & & & & & \end{array}$

20. Retiring

$\begin{array}{lllllllllll}1 & 2 & 3 & 4 & 5 & 6 & 7 & 8 & 9 & 10 & 11\end{array}$




\section{Appendix C}

Instructions and Situational Phrases Used in Phase 2

The following is a list of 80 situational phrases. Please use the scale presented below to rate the relevance of the characteristic on the paper you have been given to the situation. More specifically, how much influence do you feel this characteristic has on a person's performance (good or bad) in the situation? For example, the characteristic "reliable" and the characteristic "undependable" would both be relevant to the situation "complete assignments on time." Fill in your answers on the scan sheet provided. When you have finished, please see me.

1: Not Relevant

2: Slightly Relevant

3: Moderately Relevant

4: Reasonably Relevant

5: Very Relevant 
1. Leading group meetings

2. Working with a group to complete a complex task

3. Prioritizing a list of tasks

4. Working unassisted on a creative task

5. Reporting to work for every scheduled shift

6. Following orders given by superiors

7. Remaining calm while assisting irate customers

8. Completing assigned tasks by their deadlines

9. Resolving conflicts between subordinates

10. Working in a group as a member (not leader)

11. Getting started with necessary tasks without being given direction

12. Working on the sales floor assisting customers

13. Performing monotonous tasks

14. Clearly communicating ideas in group settings

15. Reporting for work on time

16. Remaining calm and composed while presenting ideas to a group of peers

17. Delegating responsibilities to a group

18. Working on problem solving tasks alone

19. Adjusting to a changing work environment

20. Learning new technology

21. Reporting inappropriate/illegal behavior

22. Resolving conflicts between self and peer

23. Following policies and procedures of the organization

24. Resolving conflict within a group

25. Attending an organization's social functions

26. Mentoring a new employee

27. Working in an organization with a high level of diversity

28. Accepting criticism from a superior

29. Performing several tasks at once (multitasking)

30 . Working on a project that is very detailed and precise

31. Helping to create an atmosphere of comfort in the workplace 
32. Following specific guidelines when completing a task

33. Staying focused on a task while working alone

34. Working on extremely important projects for an organization

35. Giving constructive criticism to a subordinate

36. Helping coworkers in your spare time

37. Getting less recognition than you deserve for your work on a project

38. Receiving a promotion

39. Performing tasks that are not a part of your job description

40. Contacting potential customers to sell a product

41. Persuading a group to use your ideas

42. Learning from a formal training program

43. Discussing your performance appraisal with your supervisor

44. Keeping group discussions from digressing

45. Requesting a promotion or pay raise

46. Dealing with insubordination

47. Explaining things from an employee perspective (rather than employer perspective)

48. Answering office email from home

49. Organizing company get-togethers

50. Finding creative solutions to difficult problems

51. Sharing an office with a coworker

52. Dealing with children while at work

53. Providing courteous service to customers

54. Motivating fellow group members to pitch in when working on group tasks

55. Receiving credit for an idea that wasn't yours

56. Generating ideas on the spot

57. Working with people you have never met before

58. Filling out paperwork accurately

59. Staying focused on a task while working in a group

60. Being assigned a task that makes you uncomfortable

61. Adhering to your ethical principles, even if they go against an organizational policy or procedure 
62. Following the guidelines for appropriate attire

63. Performing tasks without being asked

64. Approaching superiors with ideas to benefit the organization

65. Performing disgusting tasks (cleaning toilets or taking out trash)

66. Dealing with harassment by another employee

67. Requesting time off

68. Ensuring the safety of fellow employees and customers

69. Providing services to diverse clients/customers

70. Resolving customer complaints

71. Working with people that you don't really like

72. Conducting interviews of job candidates

73. Being able to smile even when you are upset or angry

74. Filling in for employees who are absent

75. Providing instructions to a new employee

76. Taking responsibility for substandard outcomes

77. Using humor to lighten up a tense situation

78. Calling in "sick" only when it is legitimate

79. Designing artistic media to use when presenting an idea

80. Adjusting your behavior to be appropriate in a given situation 


\section{Appendix D}

Instructions and Self-Efficacy Items Used in Phase 3

This survey contains 80 questions that describe detailed work scenarios. Each question will ask that you rate your confidence regarding performance of the task in the context described. Rate your degree of confidence that you could successfully complete the task described by recording a number from 0 to 100 using the scale given below:

$\begin{array}{lllllllllll}0 & 10 & 20 & 30 & 40 & 50 & 60 & 70 & 80 & 90 & 100\end{array}$

Cannot Moderately Highly certain

do at all can do can do

1. You have been selected as the leader of a newly formed group of employees in the large organization that you work for. How confident are you that you could lead this group of people that you have never met before in introductions and discussion of a current problem?

2. You are the member of a group working on a highly complex task (such as designing a new hybrid automobile). How confident are you that you could work with the group to complete this task?

3. You are an employee in the human resources department of a large organization. Your inbox (tasks that must be completed) contains several projects of varying importance. How confident are you that you could prioritize these tasks in order to complete those of the highest importance first and save those projects that are the least important for last?

4. You have been assigned to develop a marketing strategy for a newly developed product. This task requires a high level of creative thinking. How confident are you that you could think creatively without assistance to develop this marketing idea?

5. Attendance is very important to the organization you have just begun working for. How confident are you that you could report for work every day?

6. You are a team member working in an assembly plant. It is very important that you follow any orders given by your supervisor. How confident are you that you could listen and follow orders from your supervisor?

7. You are a customer service representative answering customer phone calls for a large organization. You frequently are required to deal with irate customers. How confident are you that you could remain calm while dealing with these customers? 
8. The work that you are required to perform is vital to your organization and has strict deadlines for completion. How confident are you that you can consistently complete your assigned tasks by their deadlines?

9. You are the supervisor of a team of 25 employees with various backgrounds. How confident are you that you could resolve a conflict between two or more of your subordinates?

10. You are the member of a medium sized work team (10-15 members). How confident are you that you could work as a member of this team, providing valuable input and completing assigned tasks?

11. You are an employee of a large organization. Your position is highly autonomous (you don't have a direct supervisor). How confident are you that you could start work on necessary tasks upon arriving at the office without being given a direct instruction to do so?

12. You are a sales representative for a large organization. How confident are you that you could approach a customer in order to assist them and make a sale?

13. You are working on an assembly line in a manufacturing plant. Your job is to tighten four screws on the product. How confident are you that you could perform this monotonous task for 40 hours a week?

14. You are a member in a medium sized work group (10-15 members). How confident are you that you could communicate your ideas clearly and effectively to the group?

15. You are an employee at a small, locally owned store. You have been scheduled for the morning shift and are responsible for opening the store on time. How confident are you that you could report to the store on time for your opening shift every day?

16. You have been asked to prepare a brief presentation about a new marketing strategy that you have come up with. How confident are you that you could remain calm and composed while presenting your idea to a large group of your peers?

17. You have been assigned to manage a small work team (4-5 members). Your task is highly complex and includes several smaller tasks to be done simultaneously, later to be combined into the final product. How confident are you that you could delegate tasks to each member of the work team? 
18. You are the CEO of a medium sized organization. It is your responsibility to solve minor problems that don't require approval from board members. How confident are you that you could work on solving these minor problems without help from others?

19. You are working for an organization that is currently going through several major changes (i.e., new ownership, downsizing, etc.). You receive memos daily regarding policy and procedure changes. How confident are you that you could adjust quickly to these changes while maintaining a high level of performance?

20. You are working for an organization that values "cutting edge" technology. Approximately every six months you are required to learn a new computing system with little individual training. How confident are you that you could learn this new technology?

21. You are a team member for a large organization. Recently, you witnessed another team member engaging in inappropriate or illegal behavior. How confident are you that you could follow the procedures to report this behavior?

22. You are an employee at a small organization. You and a fellow employee have been engaged in conflict for some time. How confident are you that you could resolve this conflict between yourself and your peer?

23. You a new employee working for a medium sized organization. You have just received the organization's policies and procedures handbook. How confident are you that you could follow the policies and procedures laid out in this handbook?

24. You are a member of a medium sized work team. Several of the members of the group are engaged in conflict regarding the best way to proceed on a complex task. How confident are you that you could resolve this conflict?

25. You are an employee at a large organization. Every year, your organization has its annual holiday party. How confident are you that you could attend this party on a yearly basis?

26. You are known as one of the best employees of a medium sized organization. You have been asked to mentor a new employee. How confident are you that you could act as a mentor to this new hire?

27. You are working for a large organization. This organization is known for its high levels of diversity. The people you work with come from various ethnic and educational 
backgrounds. How confident are you that you could work comfortably in this highly diverse environment?

28. You are the member of a large work team. Every year, your supervisor conducts employee evaluations. How confident are you that you could accept constructive criticism from your supervisor in your evaluation?

29. You are an upper level manager for a small organization. Your responsibilities include preparing the schedule, ordering product, and conducting interviews. Many of these tasks must be done simultaneously. How confident are you that you could perform several tasks at once (multitask)?

30. You are working for a medium sized organization. It is your job to take inventory of each product on the sales floor. This job requires you to be very detailed and precise in order to get an accurate count of the product lost to theft. How confident are you that you could be detailed and precise in this task?

31. You are working for a small, locally owned organization. Comfort in the workplace is highly valued. How confident are you that you could help to create an atmosphere of comfort?

32. You are working for a manufacturing plant. Your job is very complicated, so you must follow specific guidelines while you are working. How confident are you that you could consistently follow these guidelines, rather than taking shortcuts?

33. You are working for an accounting firm. Your job is entirely autonomous (you have no direct supervisor). How confident are you that you could stay focused while working alone all day?

34. You are an upper level manager for a large organization. Your job requires that you consistently work on extremely important projects. How confident are you that you could handle working on these projects?

35. You are the supervisor of a large work team. One of your responsibilities is to conduct annual performance evaluations for your team members. How confident are you that you could give constructive criticism to your subordinates?

36. You are an employee in a very busy office environment. Each day, you are given a series of tasks that must be completed. Sometimes, you are able to complete all of your 
assigned tasks early. How confident are you that you could help your coworkers complete their tasks after you have finished yours?

37. You have been working with a team on a very large, important, complex project for several weeks. Most of the ideas that have been used were yours. However, when the group leader presented the project to your manager, he took most of the credit. How confident are you that you could handle getting less recognition on a project than you deserve?

38. You have been working in an entry level position at a medium sized organization for over a year. How confident are you that you could receive a promotion?

39. You are working as an assistant to the $\mathrm{CEO}$ of a large organization. Your responsibilities include typing memos and answering phone calls. However, your boss has asked you to complete several tasks that are not specifically in your job description (cleaning the office kitchen and bathroom, for example). How confident are you that you could complete these tasks?

40. You are working as a sales representative for a travel agency. Your responsibilities include contacting individuals referred by current customers. How confident are you that you could contact these potential customers in order to sell a travel plan?

41. You are a member of a work group required to solve an important problem for your organization. You have an idea that you believe could revolutionize your organization. How confident are you that you could persuade the group to use your idea?

42. Your organization has implemented several changes to its operating procedures. Every employee is required to attend a formal training program designed to inform every one of these changes. How confident are you that you could learn from this type of training program?

43. You have been working for an organization for one year. You have just received your annual performance evaluation from your supervisor. How confident are you that you can discuss your performance appraisal with your supervisor?

44. You are a member of a work group designed to prepare a department budget. Several members of the group have been friends for years and tend to get off track with office gossip. How confident are you that you could keep the group from digressing? 
45. You have been working in the same position for the past year. You feel that you have proven yourself to be a hard worker and all around good employee. How confident are you that you could ask your supervisor for a promotion or pay raise?

46. You are the supervisor of a small work team. One of the members of your team is consistently late to meetings and does not complete his assignments. How confident are you that you could deal with this insubordination?

47. You are the manager of a medium sized organization. One of your responsibilities is to communicate any organizational changes to your employees. How confident are you that you could explain these changes from an employee perspective rather than an "employer perspective"?

48. You work in a very busy office environment for a sales company. Very often, you have so many meetings and other tasks to do during the day that you are unable to answer all of your office email. How confident are you that you could answer your email from home after work?

49. You are the public relations director for a medium sized organization. One of your responsibilities is to organize company get-togethers (including an annual holiday party). How confident are you that you could complete this task?

50. You are a member of the research and development team of a large organization. This position requires that you find creative solutions to difficult problems in order to design new products and services. How confident are you that you can find creative solutions to difficult problems?

51. You are working for a small retail sales organization. Recently, your organization had to downsize and is now renting out half of its building space. You are now required to share an office with another employee. How confident are you that you could share an office with a coworker?

52. You are an employee in a family friendly office. Employees are allowed to bring in their children when daycares or schools are closed. How confident are you that you could deal with children while you are working?

53. You are a customer service representative for a large computer retail company. Your job is to answer customer phone calls to take orders and answer questions. How confident are you that you could provide courteous service to these customers? 
54. You are a member of a large work team designed to brainstorm new product ideas. Several of the other members of the team have not contributed to the group. How confident are you that you could motivate these group members to pitch in with the group's task?

55. You are the leader of a work team. For several months, your team has been working on a new product design that shows great promise to increase revenue to your organization. The idea was generated by one of the members on your team. When you present the product design to your boss, he credits you for the idea. How confident are you that you could receive credit for an idea that wasn't yours?

56. You are an employee in the technology industry. You are constantly in meetings where you are asked to brainstorm solutions to various problems that can result in new types of technology. How confident are you that you could generate ideas quickly while on the spot?

57. You are the newest member of a large work team in a retail organization. How confident are you that you could work with people you have never met before?

58. You are working as a managerial assistant. Your responsibilities include filling out several important documents on a daily basis. How confident are you that you could fill out this paperwork accurately?

59. You are the member of a work group designed to complete a series of tasks on a daily basis. You work with this group most of the time that you are at work. How confident are you that you could stay focused and on task while working with this group?

60. You are working for a marketing firm that designs marketing strategies for several organizations. You have recently been assigned to create a new series of commercials for a product that you would never support. How confident are you that you could complete this task even though it makes you feel uncomfortable?

61. You are a sales representative for a large investment firm. One of the policies of the organization is to attempt to sell any stock by any means necessary. This often requires misleading customers by providing false hopes of large returns on their investments. You believe this policy is unethical. How confident are you that you could adhere to your ethical principles rather than following the organization's policy in this matter? 
62. You are working for a very conservative organization. There are strict guidelines for appropriate attire. How confident are you that you could follow these guidelines?

63. You are an employee in a small sit-down restaurant. There are always several tasks that need to be completed. How confident are you that you could perform these tasks without being asked?

64. You are working in an entry level position for a large organization. You have several ideas that could improve the performance of the organization. How confident are you that you could approach your supervisor with your ideas to benefit the organization?

65. You are working for a fast food restaurant. There are several disgusting tasks that need to be performed on a regular basis (cleaning toilets or taking out the trash). How confident are you that you could perform these tasks?

66. You are working in a busy office. At the water cooler, another employee makes an inappropriate comment about your body. You perceive this comment as sexual harassment. How confident are you that you could deal with harassment by another employee?

67. You have been working for an organization for a few months. Your birthday is coming up next month so you would like to take a couple days off from work. How confident are you that you could request time off?

68. You are working in a large manufacturing plant. The equipment and materials are very hazardous if used inappropriately. How confident are you that you could ensure the safety of those around you?

69. You are working as a customer service representative for a large organization. Your clients/customers come from diverse backgrounds. How confident are you that you could provide the same level of professional service to each of these individuals?

70. You are working on the sales floor for a retail outlet. One of your responsibilities is to handle customer complaints. How confident are you that you could deal with these upset customers effectively?

71. You are a member of a small work team. One of the other team members is someone you have hated since high school. How confident are you that you could work productively in this group with someone you don't like? 
72. You are an employee in the human resource department of a large organization. One of your responsibilities is to interview potential employees. How confident are you that you could conduct employment interviews of job candidates?

73. You have been working for the same organization for several years. Recently, you have been going through several changes at home (divorce, death of a loved one, etc). You are frequently upset or angry. How confident are you that you could continue to smile at work instead of letting your true emotions show?

74. You are an employee in a busy office. Each employee in your office is assigned several tasks to complete each day. One of your coworkers has been out sick for the last few days and has work that needs to be completed. How confident are you that you could fill in for your coworker?

75. You are the line supervisor at a manufacturing plant. You have just been assigned a new employee. How confident are you that you could provide instruction/training to this employee?

76. You are working on an assembly line. It is your responsibility to inspect the final products that come off the line before sending them to be packaged and shipped.

Recently, several shipments have been returned. How confident are you that you could take responsibility for these substandard products?

77. You are working as a registered nurse in the emergency room of a large hospital. Often, you are involved in very tense situations. How confident are you that you could use humor appropriately to lighten up a tense situation?

78. You are working for a small, locally owned company. Attendance is very important, as there are not many employees that can fill in for an absent employee. How confident are you that you could call in sick only when you are truly sick?

79. You are working in the marketing department of a large organization. Your job requires that you give several presentations of new strategies. How confident are you that you could design artistic media to use when giving these presentations?

80. You are an employee in a very dynamic environment, having to travel to several different countries regularly. You often find yourself in situations that you have never experienced before. How confident are you that you could adjust your behavior using cues in your environment to be appropriate in a novel situation? 


\section{Footnotes}

1 The terms "schema," "attribute," and "characteristic" are used in this manuscript interchangeably.

2 The terms "schema," "attribute," and "characteristic" are used to refer to both self-relevant and normative characteristics unless otherwise specified. 
Table 1. Frequency Distribution of Attributes in Phase 1.

\begin{tabular}{|c|c|c|c|c|}
\hline Characteristic & Strength & Normative & Weakness & Total \\
\hline Hard Working & 71 & 246 & 13 & 330 \\
\hline Reliable & 71 & 185 & 2 & 258 \\
\hline Sociable & 38 & 188 & 26 & 252 \\
\hline Good Natured & 51 & 30 & 5 & 86 \\
\hline Organized & 49 & 6 & 7 & 62 \\
\hline Friendly & 34 & 0 & 2 & 36 \\
\hline At Ease & 16 & 0 & 20 & 36 \\
\hline Patient & 9 & 0 & 17 & 26 \\
\hline Independent & 24 & 0 & 1 & 25 \\
\hline Secure & 13 & 0 & 12 & 25 \\
\hline Fun Loving & 24 & 0 & 0 & 24 \\
\hline Self-Motivated & 16 & 0 & 5 & 21 \\
\hline Personable & 18 & 0 & 1 & 19 \\
\hline Careful & 10 & 0 & 9 & 19 \\
\hline Punctual & 7 & 0 & 12 & 19 \\
\hline Soft Hearted & 14 & 0 & 3 & 17 \\
\hline Talkative & 3 & 0 & 13 & 16 \\
\hline Curious & 12 & 0 & 3 & 15 \\
\hline Responsible & 14 & 0 & 1 & 15 \\
\hline Sympathetic & 9 & 0 & 6 & 15 \\
\hline Determined & 13 & 0 & 2 & 15 \\
\hline Perfectionist & 2 & 0 & 12 & 14 \\
\hline Distractible & 3 & 0 & 11 & 14 \\
\hline Frustrated & 0 & 0 & 14 & 14 \\
\hline Self-Disciplined & 1 & 0 & 11 & 12 \\
\hline Respectful & 4 & 0 & 8 & 12 \\
\hline Assertive & 0 & 0 & 11 & 11 \\
\hline Forgiving & 10 & 0 & 0 & 10 \\
\hline Efficient & 8 & 0 & 1 & 9 \\
\hline Self-Conscious & 7 & 0 & 2 & 9 \\
\hline Cooperative & 8 & 0 & 1 & 9 \\
\hline Leadership & 7 & 0 & 1 & 8 \\
\hline Conservative & 8 & 0 & 0 & 8 \\
\hline Dedicated & 7 & 0 & 1 & 8 \\
\hline Emotional & 0 & 0 & 8 & 8 \\
\hline Temper & 0 & 0 & 7 & 7 \\
\hline Bored & 0 & 0 & 7 & 7 \\
\hline Enthusiastic & 5 & 0 & 1 & 6 \\
\hline Conscientious & 6 & 0 & 0 & 6 \\
\hline High Expectations & 1 & 0 & 5 & 6 \\
\hline Stubborn & 0 & 0 & 6 & 6 \\
\hline Liberal & 6 & 0 & 0 & 6 \\
\hline People Pleaser & 0 & 0 & 5 & 5 \\
\hline Creative & 5 & 0 & 0 & 5 \\
\hline Stressed & 1 & 0 & 3 & 4 \\
\hline Adaptive & 2 & 0 & 2 & 4 \\
\hline Detail Oriented & 2 & 0 & 1 & 3 \\
\hline Forgetful & 0 & 0 & 3 & 3 \\
\hline Overachieving & 2 & 0 & 1 & 3 \\
\hline Aggressive & 0 & 0 & 3 & 3 \\
\hline Bossy & 0 & 0 & 3 & 3 \\
\hline Honest & 3 & 0 & 0 & 3 \\
\hline Loner & 0 & 0 & 3 & 3 \\
\hline
\end{tabular}


Architecture of Work Personality 65

\begin{tabular}{|c|c|c|c|c|}
\hline Opinionated & 0 & 0 & 3 & 3 \\
\hline Humorous & 3 & 0 & 0 & 3 \\
\hline Indecisive & 0 & 0 & 3 & 3 \\
\hline Upset & 0 & 0 & 2 & 2 \\
\hline Easily Discouraged & 0 & 0 & 2 & 2 \\
\hline Moody & 0 & 0 & 2 & 2 \\
\hline Loyal & 2 & 0 & 0 & 2 \\
\hline Helpful & 1 & 0 & 1 & 2 \\
\hline Empathetic & 1 & 0 & 1 & 2 \\
\hline Selfish & 0 & 0 & 2 & 2 \\
\hline Confrontational & 0 & 0 & 2 & 2 \\
\hline Critical & 0 & 0 & 2 & 2 \\
\hline Complacent & 0 & 0 & 2 & 2 \\
\hline Extroverted & 1 & 0 & 1 & 2 \\
\hline Pride & 0 & 0 & 2 & 2 \\
\hline Optimistic & 2 & 0 & 0 & 2 \\
\hline Time Management & 2 & 0 & 0 & 2 \\
\hline Learning Differences & 0 & 0 & 2 & 2 \\
\hline Bad Attitude & 0 & 0 & 2 & 2 \\
\hline Competitive & 1 & 0 & 1 & 2 \\
\hline Approachable & 0 & 0 & 1 & 1 \\
\hline Courteous & 1 & 0 & 0 & 1 \\
\hline Particular & 0 & 0 & 1 & 1 \\
\hline Perceptive & 1 & 0 & 0 & 1 \\
\hline Superior & 1 & 0 & 0 & 1 \\
\hline Skeptical & 0 & 0 & 1 & 1 \\
\hline Persuasive & 0 & 0 & 1 & 1 \\
\hline Sarcastic & 0 & 0 & 1 & 1 \\
\hline Admirable & 1 & 0 & 0 & 1 \\
\hline Controlling & 0 & 0 & 1 & 1 \\
\hline Hypocritical & 0 & 0 & 1 & 1 \\
\hline Listener & 1 & 0 & 0 & 1 \\
\hline Willing & 1 & 0 & 0 & 1 \\
\hline Trust-worthy & 1 & 0 & 0 & 1 \\
\hline Self-involvement & 0 & 0 & 1 & 1 \\
\hline Strong & 1 & 0 & 0 & 1 \\
\hline Agreeable & 1 & 0 & 0 & 1 \\
\hline Open Minded & 1 & 0 & 0 & 1 \\
\hline Ambitious & 1 & 0 & 0 & 1 \\
\hline Nurturing & 1 & 0 & 0 & 1 \\
\hline Cheerful & 1 & 0 & 0 & 1 \\
\hline Chicken & 0 & 0 & 1 & 1 \\
\hline Tired & 0 & 0 & 1 & 1 \\
\hline Overwhelmed easily & 0 & 0 & 1 & 1 \\
\hline Compulsive & 0 & 0 & 1 & 1 \\
\hline Diplomatic & 1 & 0 & 0 & 1 \\
\hline Unattached & 0 & 0 & 1 & 1 \\
\hline Over-Commitment & 0 & 0 & 1 & 1 \\
\hline Total & 641 & 655 & 335 & 1631 \\
\hline
\end{tabular}


Table 2. Frequency of Responses to Characteristics in Phase 2.

\begin{tabular}{lllll}
\hline Characteristic & Strength & Normative & Weakness & Total \\
\hline Hard Working & 54 & 182 & 6 & 242 \\
Dependability & 62 & 139 & 2 & 203 \\
Gregariousness & 29 & 133 & 20 & 182 \\
Good Natured & 40 & 21 & 4 & 65 \\
Organized & 34 & 5 & 4 & 43 \\
Amiable & 39 & 0 & 3 & 42 \\
Cooperation & 12 & 0 & 15 & 27 \\
At Ease & 9 & 0 & 20 & 29 \\
Secure & 14 & 0 & 13 & 27 \\
Empathy & 16 & 0 & 5 & 21 \\
Independent & 20 & 0 & 1 & 21 \\
Fun Loving & 17 & 0 & 0 & 17 \\
Efficiency & 8 & 0 & 5 & 13 \\
Self-Motivated & 12 & 0 & 4 & 16 \\
Caution & 6 & 0 & 7 & 13 \\
Punctuality & 4 & 0 & 8 & 12 \\
Soft Hearted & 13 & 0 & 2 & 15 \\
Precision & 4 & 0 & 11 & 15 \\
Frustrated & 0 & 0 & 14 & 14 \\
Talkativeness & 2 & 0 & 11 & 13 \\
Curious & 8 & 0 & 2 & 10 \\
Determined & 9 & 0 & 2 & 11 \\
Distractible & 2 & 0 & 7 & 9 \\
Courtesy & 6 & 0 & 6 & 12 \\
Dedicated & 5 & 0 & 2 & 7 \\
Assertive & 0 & 0 & 8 & 8 \\
Bossiness & 0 & 0 & 5 & 5 \\
Leadership & 4 & 0 & 1 & 5 \\
Conservative & 6 & 0 & 0 & 6 \\
Emotional & 0 & 0 & 7 & 7 \\
Flexibility & 1 & 0 & 5 & 6 \\
People Pleaser & 0 & 0 & 5 & 5 \\
Temper & 0 & 0 & 5 & 5 \\
Bored & 0 & 0 & 5 & 5 \\
Spirit & 5 & 0 & 1 & 6 \\
Stubborn & 0 & 0 & 3 & 3 \\
Liberal & 4 & 0 & 0 & 4 \\
Egotistical & 1 & 0 & 4 & 5 \\
Creative & 5 & 0 & 0 & 5 \\
Morality & 3 & 0 & 1 & 4 \\
Aloof & 1 & 0 & 3 & 4 \\
Over-Achieving & 2 & 0 & 1 & 3 \\
\hline Total & 457 & 480 & 228 & 1165 \\
\hline
\end{tabular}


Table 3. Number of Situations Rated as Relevant by Individuals Possessing the Characteristic (Schematic) and Individuals Rating the Characteristic Normatively (Normative), the Number of Overlapping Ratings and the Agreement between Each Group.

\begin{tabular}{lllllll}
\hline Characteristic & \multicolumn{7}{l}{ Schematic } & \multicolumn{2}{l}{ Normative } \\
\hline & $\mathrm{N}$ & $\mathrm{R}$ & $\mathrm{N}$ & $\#$ & Overlap & Agreement \\
\hline Hard Working & 61 & 2 & 182 & 6 & 2 & $100 \%$ \\
Gregariousness & 48 & 3 & 133 & 8 & 3 & $100 \%$ \\
Dependability & 52 & 6 & 139 & 4 & 4 & $67 \%$ \\
Good Natured & 43 & 2 & 21 & 8 & 2 & $100 \%$ \\
Organized & 38 & 7 & 5 & 4 & 3 & $43 \%$ \\
\hline
\end{tabular}

$\mathrm{N}=$ number of raters

$\mathrm{R}=$ number of situations rated as relevant ( 4.5 or higher) 


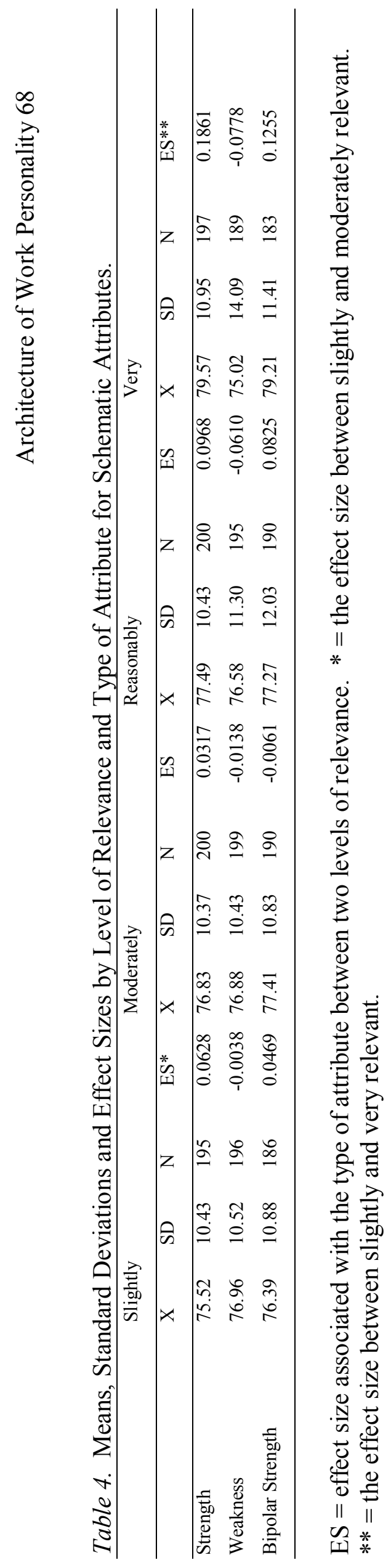




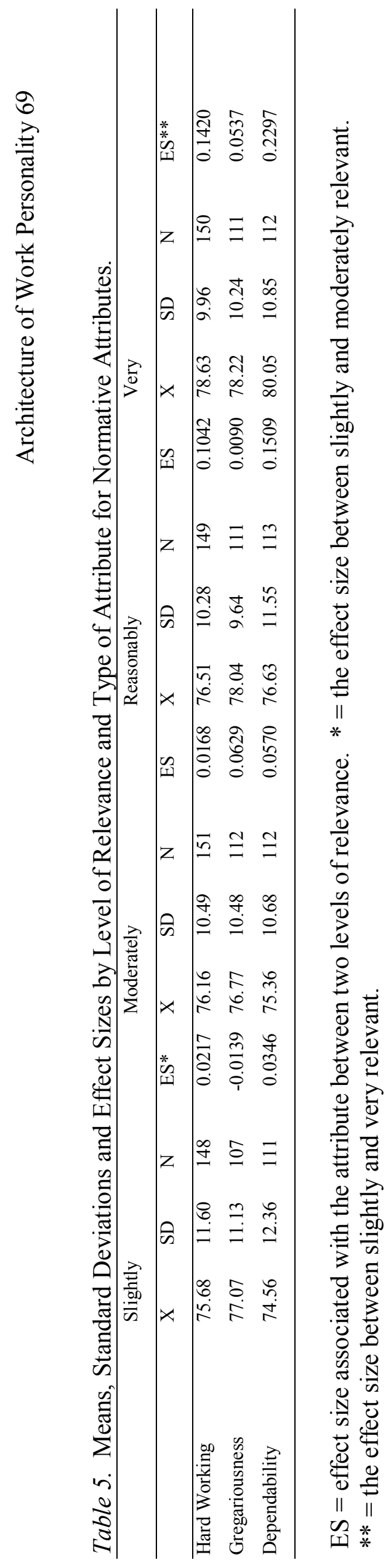


Table 6. Situations Rated as Relevant on Average by the Group of Raters for the Characteristic Gregariousness.

$1 \quad$ Leading group meetings

12 Working on the sales floor assisting customers

25 Attending an organization's social functions

$40 \quad$ Contacting potential customers to sell a product

$41 \quad$ Persuading a group to use your ideas

57 Working with people you have never met before 
Table 7. Means, Standard Deviations, and Effect Sizes for Nomothetic Analysis of the Characteristic Gregariousness.

\begin{tabular}{|c|c|c|c|c|c|c|c|c|c|c|c|c|c|}
\hline & \multicolumn{5}{|c|}{ Weakness } & \multicolumn{4}{|c|}{ Normative } & \multicolumn{4}{|c|}{ Strength } \\
\hline & $\mathrm{X}$ & $\mathrm{SD}$ & $\mathrm{N}$ & $\mathrm{ES} *$ & $\mathrm{X}$ & $\mathrm{SD}$ & $\mathrm{N}$ & $\mathrm{ES}$ & $\mathrm{X}$ & $\mathrm{SD}$ & $\mathrm{N}$ & $\mathrm{ES} * *$ & $\mathrm{p}$ \\
\hline Gregariousness & 72.18 & 15.21 & 19 & 0.1719 & 77.04 & 12.51 & 113 & 0.2091 & 82.72 & 14.01 & 19 & 0.3391 & 0.03282 \\
\hline
\end{tabular}

$\mathrm{ES}=$ effect size associated with the attribute between two levels of relevance. $*=$ the effect size between slightly and moderately relevant. ${ }^{* *}=$ the effect size between slightly and very relevant. $\mathrm{p}$ based on ANOVA between weakness and strength 
Figure 1. Illustration of one participant's three schematic characteristics with the situations she believed were most relevant to one attribute (organized) and one situation that was generally viewed as relevant to being organized, but was not rated as relevant by this participant.

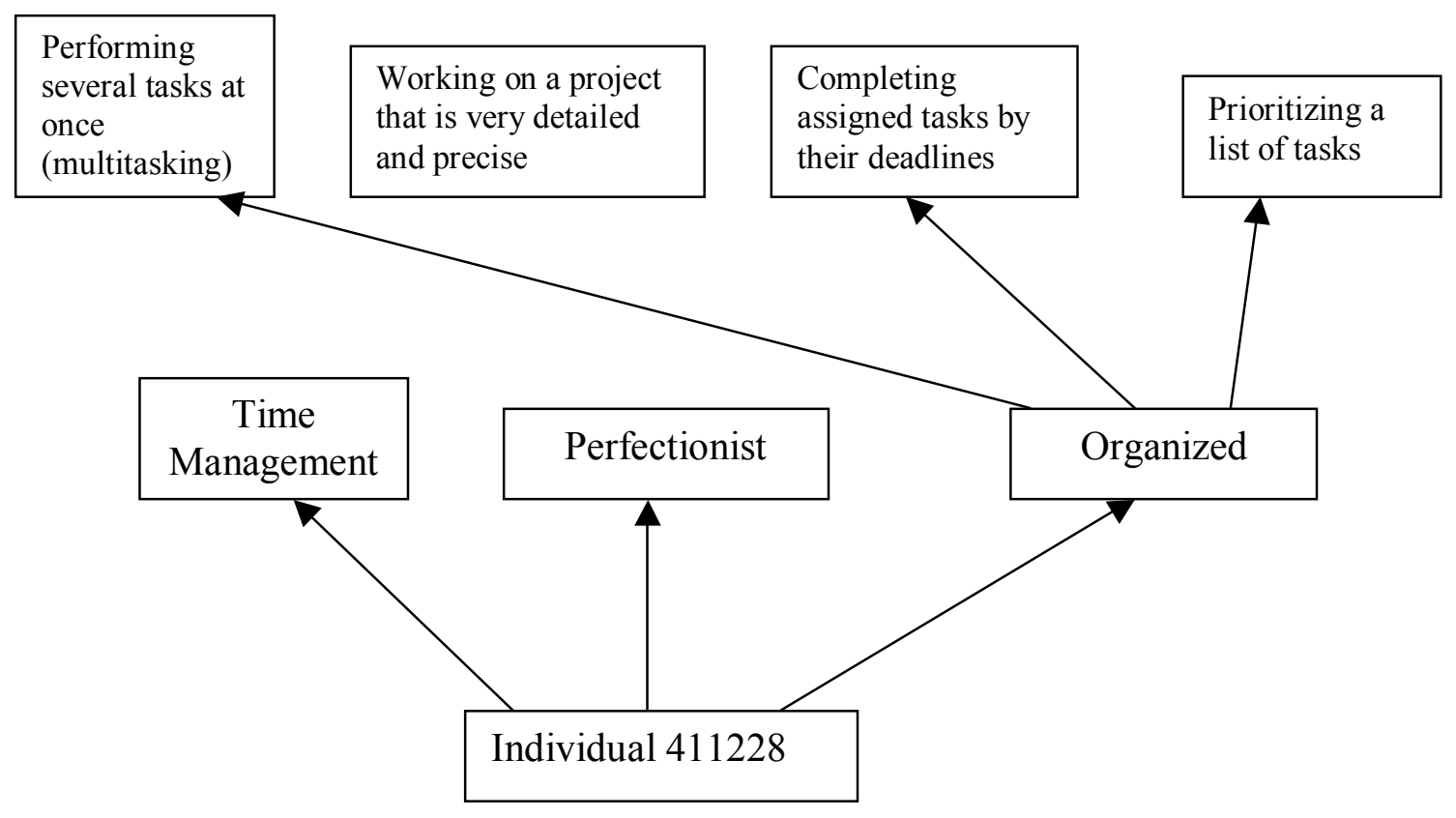


Figure 2. Illustration of two participants whose bipolar attribute was soft hearted and the situations that the participants believed to be relevant to the attribute.

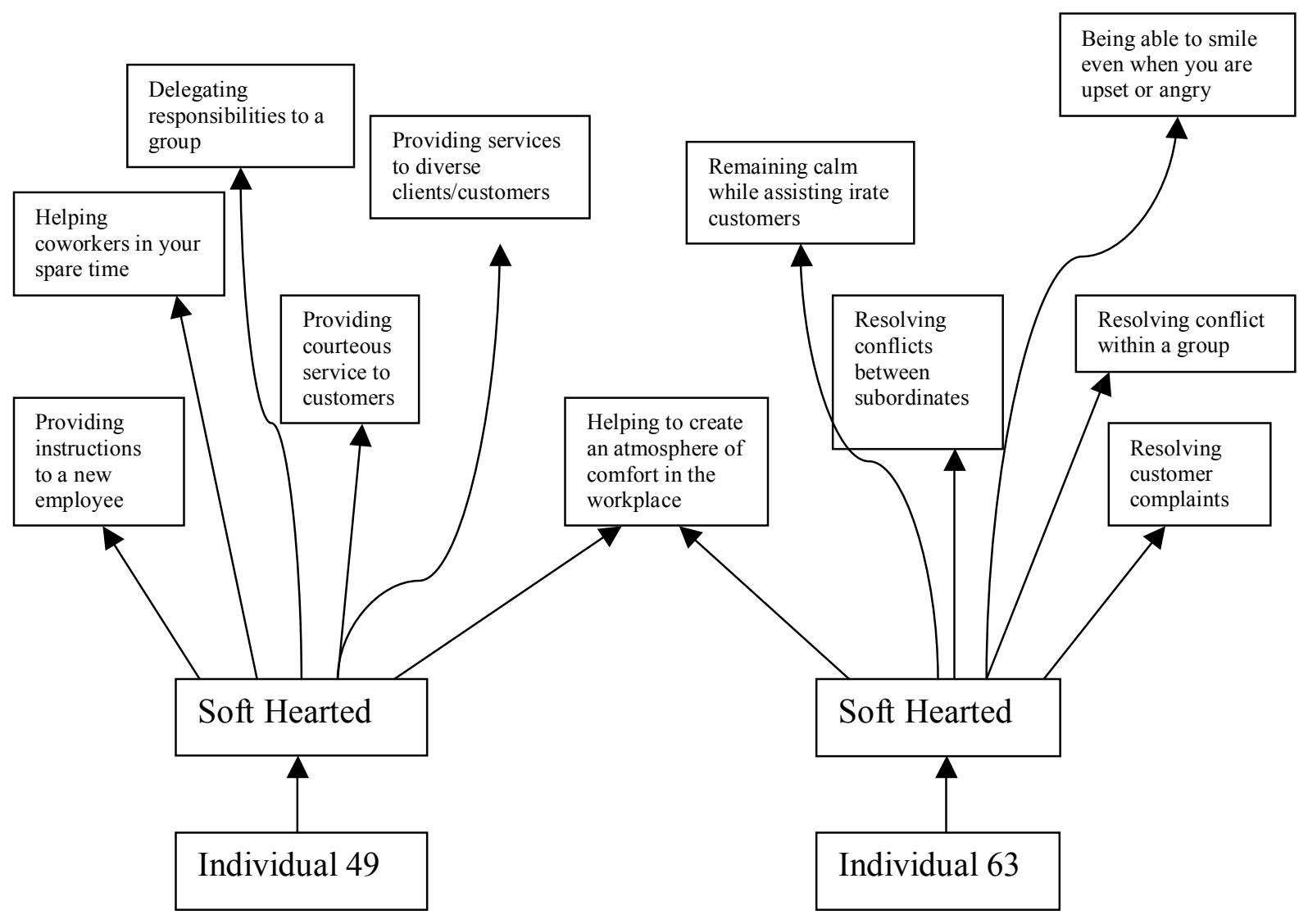


Figure 3. Illustration of two participants whose self-relevant strength was dependability and the situations that the participants believed to be relevant to the attribute.

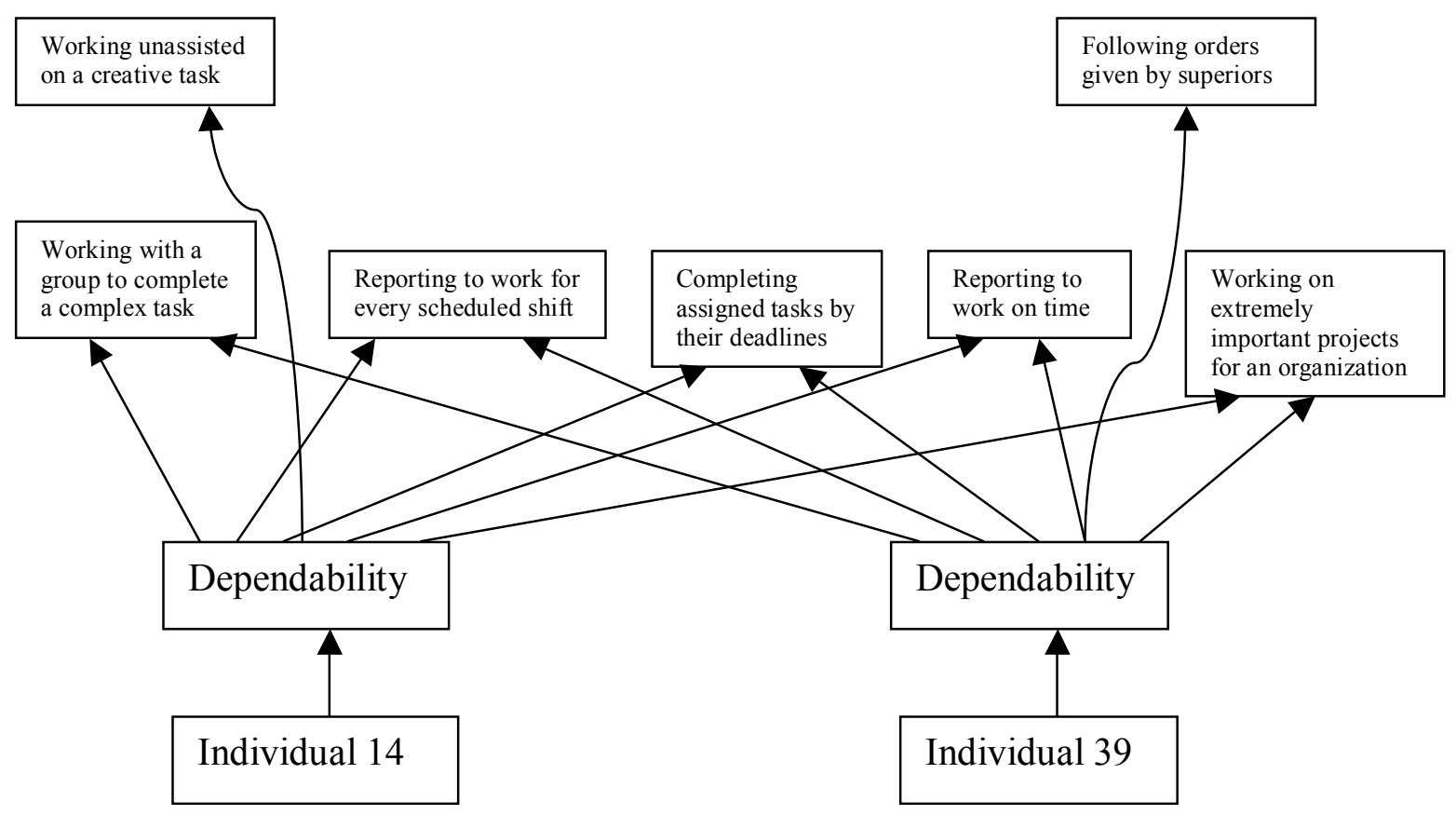


Figure 4. Average of participant's mean self-efficacy ratings (and standard error of the mean bars) on those phase 3 items related to the phase 2 situations by relevance level for schematic attributes.

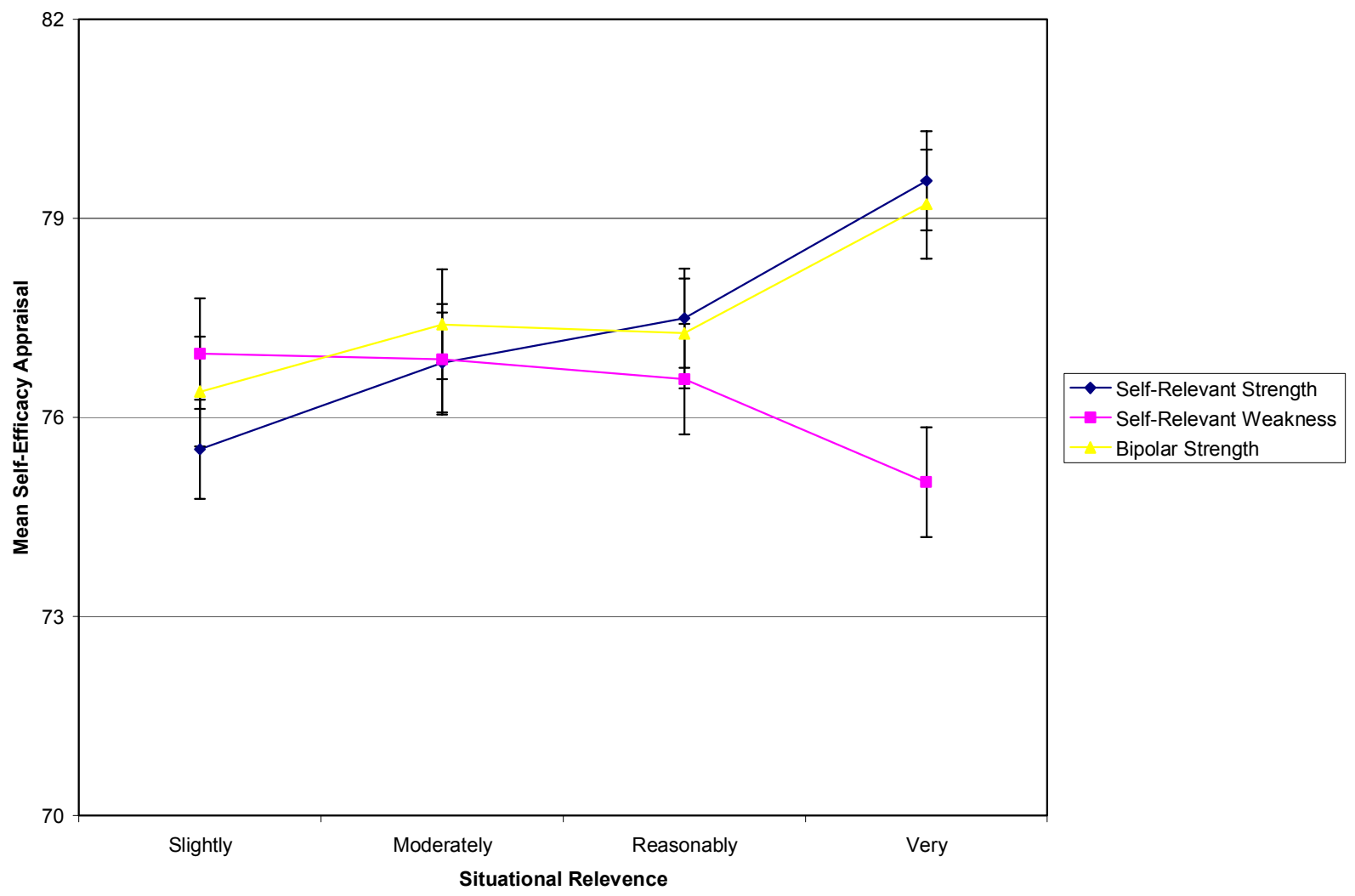


Figure 5. Average of participant's mean self-efficacy ratings (and standard error of the mean bars) on those phase 3 items related to the phase 2 situations by relevance level for normative attributes.

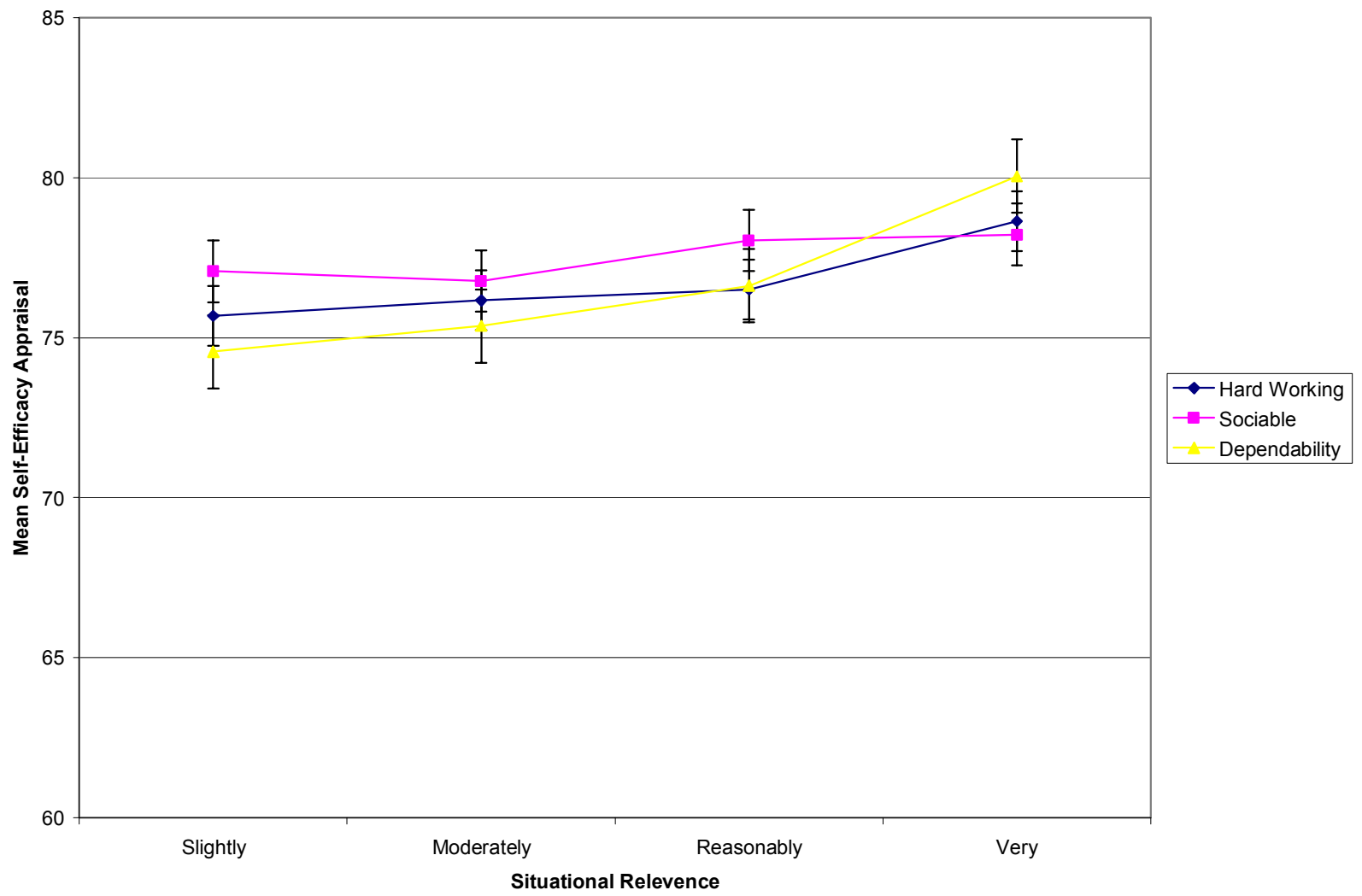


Figure 6. Comparison of Two Individuals with the Same Mean Self-Efficacy Score on a Group of Items but Differing Underlying Characteristics.

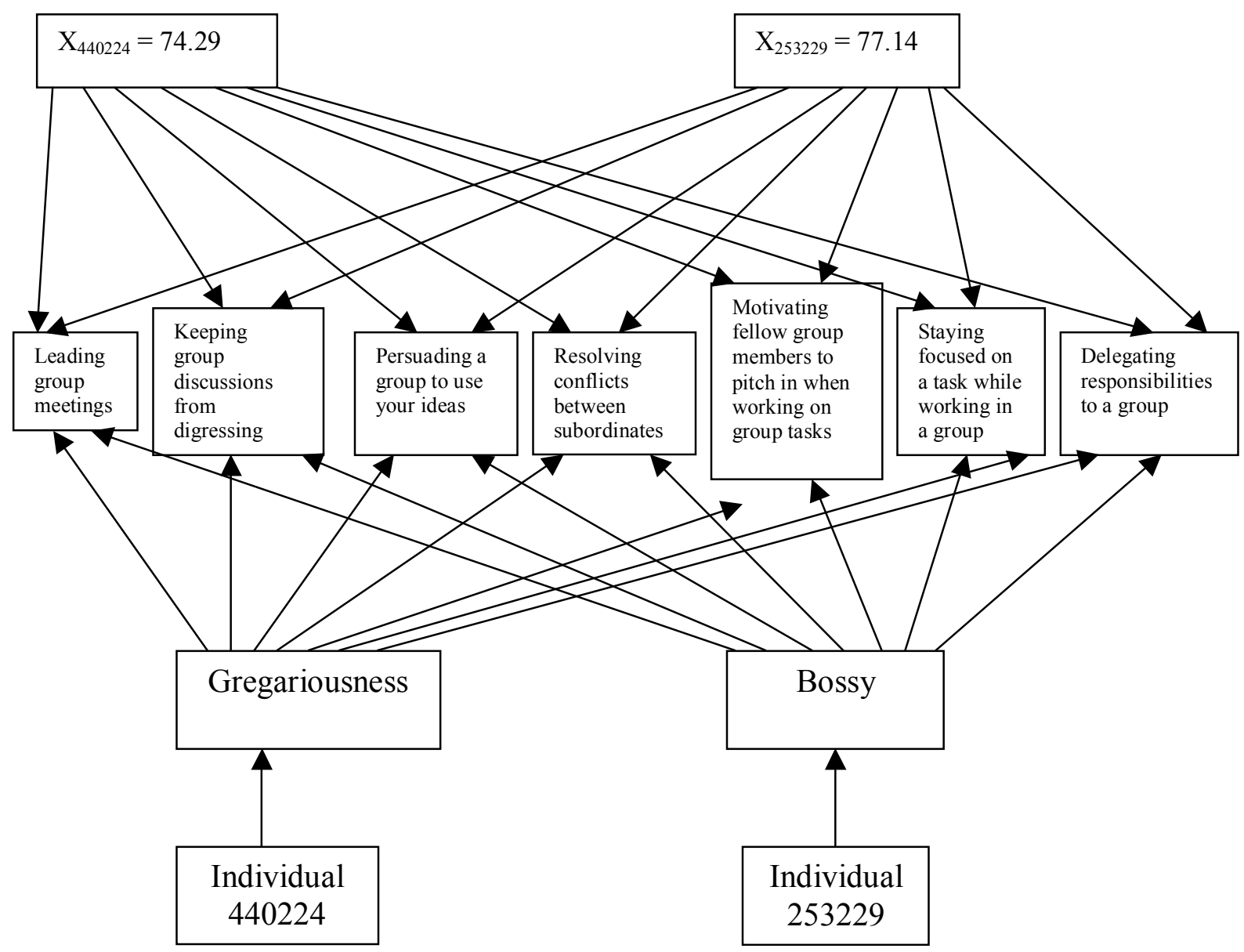


Figure 7. Mean self-efficacy appraisals for those items related to situations relevant to the characteristic Gregariousness.

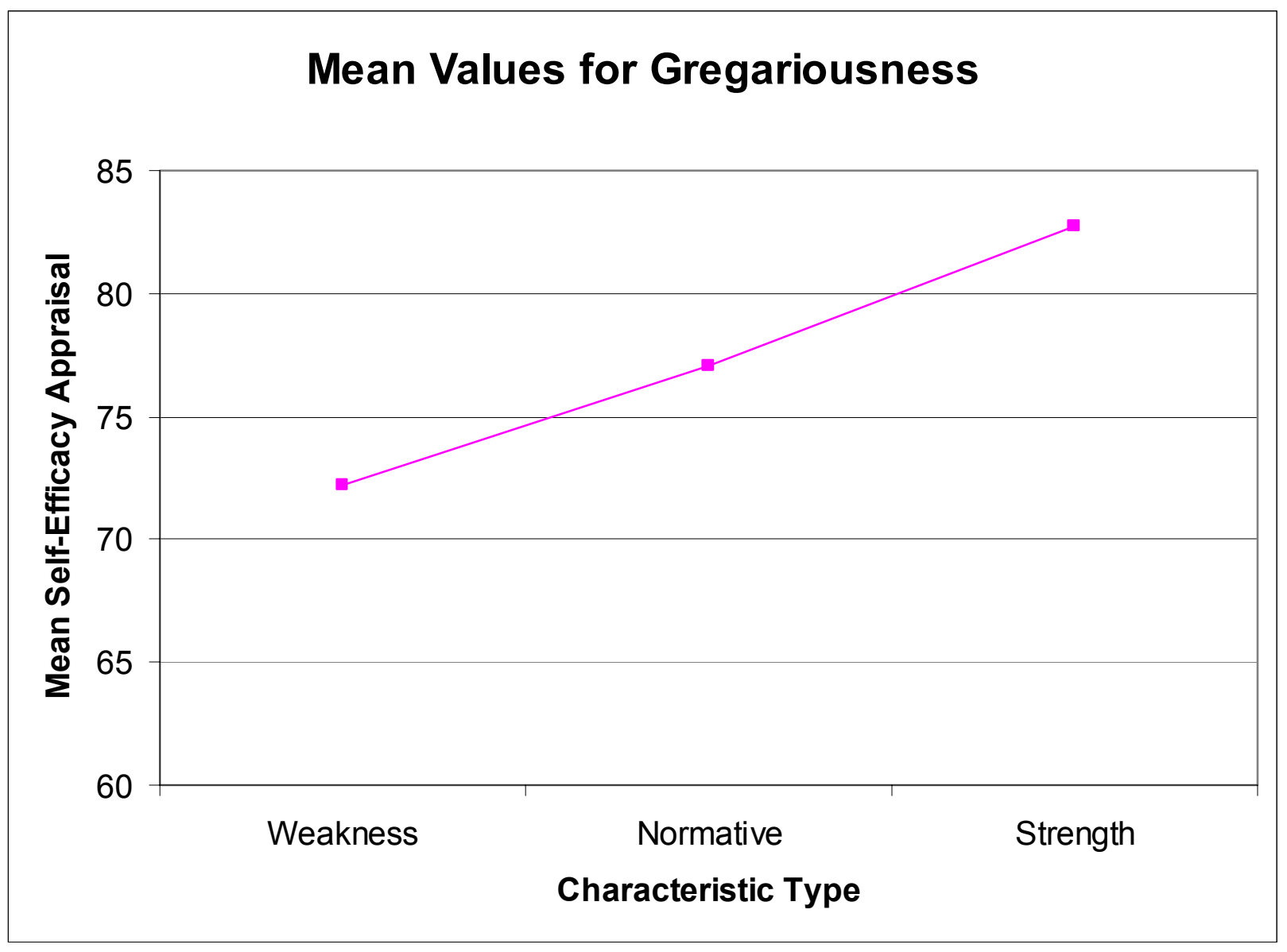

